\title{
4. What Does Scientific Argumentation Look Like?
}

Some arguments and inferences are theoretical in the sense that they are meant to show that a certain view is true or probably true, whereas others are practical in the sense that they are meant to show that one ought to act in a certain way. In both kinds of cases a certain conclusion (C) is meant to follow from some other things that are called premises $(\mathrm{P})$. Schematically: ' $P$, hence: $C$ '. Between the premises and the conclusion there is always a link of some kind; sometimes this 'hence' is called an 'inference', sometimes not. In this chapter we shall present different such links. We will mainly focus on theoretical argumentation, but some space will be devoted to practical inferences too. The former dominate in medical science, but the latter in the everyday life of clinicians.

What is a conclusion in one argument may be a premise in another. Arguments can sometimes be put together into long chains of argumentations. Even for such immaterial kinds of chains, it can hold true: no chain is stronger than its weakest link. However, arguments of different kinds can also be wired around each other, and then the weakest-link metaphor breaks down. According to the father of fallibilism, Peirce, our "reasoning should not form a chain which is no stronger than its weakest link, but a cable whose fibers may be ever so slender, provided they are sufficiently numerous and intimately connected (Peirce, p. 229).” It should be added that new epistemological situations may require new 'cables', and that this view makes argumentations situation-bound (the same kind of 'particularism' holds true also for moral reasoning, as we will explain in Chapter 9.4).

Taken in isolation, some arguments are strong and some are weak. The strongest possible theoretical link is the deductive inference, but it is only in sciences such as mathematics and logic that it makes sense to try to rely merely on deductive arguments. All the empirical sciences have to rely on weaker - and much weaker - forms of argumentations. In the empirical sciences there is fallibility and epistemic uncertainty, but, on the other 
hand, in pure logic and pure mathematics there is no contact with the world in space and time. The basic form of empirical argumentation is argumentation from perceptions. Explicitly or implicitly, we argue by saying 'I saw it!' Everyday life is impregnated with such arguments. Especially, we can be said to argue with ourselves in this way. If you want to know if it is raining, you look out the window; if you want to know if there is milk in the fridge, you open the door and look; and so on. This form of argumentation, with its tacit presupposition that most perceptions are veridical, will merely form the background for most of the things we will say in this chapter.

Perhaps in a not too distant future, this chapter will be deemed to suffer from a neglect of 'arguments by pictures' and 'arguments by diagrams'; even though we have already surpassed the view that all argumentation takes place by means of sentences. We have just noted the existence of immediate perception-assertion transitions that can take place in arguments from perceptions, and we have earlier (Chapter 3.2) noted the phenomenon of 'perceptual structuring'. Since long, physicians have argued by means of X-ray pictures; recently, computer tomography, magnetic resonance imaging (MRI), functional neuroimaging, and even other imaging technologies have entered the medical scene on a broad scale; and there seems to be good reasons to think that in the future one can even reason with the help of 'pictures' that are not real pictures but computer simulations. This being noted let us start our presentation.

\subsection{Arguments ad hominem}

Many modern advertisements tell the onlookers: 'This celebrity is doing A, hence: you ought to do A!' The point of such practical 'ads-arguments' is that we should trust the famous person in question, and behave as he is said to do. Compare with old-time medicine: the famous Hippocrates says that a good physician should do this and avoid that, therefore as a physician you ought to do so as well. This kind of argumentation has also a theoretical form: 'This celebrity claims that $S$ is true, hence: you ought to believe that $S$ is true!'; 'Einstein claims that $S$ is true, hence: you ought to believe that $S$ is true, too!' In logic, arguments of this kind are sorted out as a special kind of logically invalid arguments called arguments ad hominem, i.e., they are arguments 'to a man' instead of arguments that present axioms, 
principles, or empirical evidence. Arguments ad hominem may be persuasive, but they cannot be convincing; at least not if to be convinced of a view means being able to offer evidence in favor of this view. Marketers can rest content with persuasion, but scientists should aim at convincing. Nonetheless, science cannot do without arguments ad hominem.

Arguments ad hominem are of course often needed in the relation between scientists and laymen; much research can be judged only by experts. But they are also needed between scientists themselves. The reason is that science, like most modern enterprises, rests on a far-reaching division of labor. Not even skeptical research groups can rely only on their own reasoning and observations; they have also to trust other scientific knowledge authorities. Even though the scientific community as a whole has only two epistemological sources, observation and reason, each individual scientist and research group has three:

- observation

- reason

- trust in information from others.

All these three sources are fallible. We can make wrong observations, reason wrongly, and trust the wrong people. But we shall try to avoid it.

Perhaps trust comes primarily to mind when one thinks of small groups such as families, clans, and friend circles, but trust is central to human societies at large and to scientific communities, too. Not to speak of the relation between patients and physicians. Depending on context, an argument ad hominem can be either an attempt at pure persuasion or a necessary move in a rational process that aims at convincement. In human life, the general ad hominem structure is inevitable, but what authority we shall put in the premise as 'the man' can very much be a matter for occasional discussion. Here are four different ad hominem schemas:
(1) celebrity does A
(2) parent says ' $\mathrm{H}$ is true'

hence:

(1) I will do A

(2) I believe ' $\mathrm{H}$ is true' 
(3) physician says 'do A'

hence:
(4) scientist says ' $\mathrm{H}$ is true'

(4) I believe ' $\mathrm{H}$ is true'

Let us mention one famous example of medical trust and one of mistrust. In the 1970s, double Nobel Prize winner Linus Pauling (1901-1994) claimed that massive doses of vitamin $\mathrm{C}$ are good both for treating and preventing colds. As a result, rather immediately, many people started consuming vitamin $\mathrm{C}$ when having a cold. They simply trusted Pauling. When Max von Pettenkofer (see Chapter 2.5) claimed that he had drunk a culture of cholera bacteria without becoming ill, there was no other person who could testify this. Pettenkofer simply declared that he had done it, and he expected to be trusted. His assistant wrote to Koch:

Herr Doctor Pettenkofer presents his compliments to Herr Doctor Professor Koch and thanks him for the flask containing the socalled cholera vibrios, which he was kind enough to send. Herr Doctor Pettenkofer has now drunk the entire contents and is happy to be able to inform Herr Doctor Professor Koch that he remains in his usual good health.

But Koch seems not to have considered his letter.

Before randomized controlled trials (RCTs) in the second half of the twentieth century became the golden standard for assessing medical technologies, new medicines and surgical methods were launched only on the authority of some prominent physician. The treatments in questions were mostly based on long personal experience and not gratuitous, but they were nonetheless not evidence-based in the modern sense. This older argumentative mode, with its appeals to authoritative figures, is still frequently used when so-called complementary or alternative medical treatments are launched on the market. Personal experience is very important for both clinicians and researchers (see Chapter 5), but it is not by far - in itself a sufficient tool for assessing the effects of medical treatments.

From a social perspective, the increased use of RCTs might be regarded as a democratization of medical assessments. Since more than one person 
may influence this kind of evaluative process, both openness and corrigibility of the assessments increase.

There are since long different forms of RCTs, e.g., 'single-blind' and 'double-blind' (see Chapter 6.3), but a wholly new step in the development of RCTs was taken (starting in the early nineties) by the Cochrane Collaboration groups. These try to take account also of the fact that, often, different medical research groups that evaluate the same treatment obtain different results. Therefore, there is a need also for groups that perform meta-analyses of such conflicting RCTs. Today, the medical community is inclined to trust representatives from Cochrane groups or centers more than others when the effects and the efficacy of medical technologies are under discussion.

The first philosophical advocate of the industrial revolution, Francis Bacon, is famous for the saying 'knowledge is power'. He meant that knowledge of nature allows us to master nature. Today, it should be noted, this phrase is often given quite another meaning; or, rather, two meanings that are confounded. It is used (a) to claim that power and knowledge are socially inseparable, and in this sense the saying contains a kernel of truth. Having power in some respect often implies being able to tell what should be regarded as true in the corresponding area. Conversely, to be regarded as someone who can tell the truth is often to have a considerable amount of power. The Cochrane Collaboration groups have a kind of power. However, the saying 'knowledge is power' is also in radical social constructivist writings used (b) to claim that there is no knowledge at all in the traditional sense, only power disguising itself as knowledge. From such a curious perspective, all arguments are necessarily arguments ad hominem. We regard it as disastrous. If it is adopted, one can call all scientific argumentation, and even clinicians' diagnoses, 'symbolic terror'. Humpty Dumpty, from Alice in Wonderland, was in this sense ahead of his time when he argued with Alice:

- But 'glory’ doesn’t mean 'a nice knock-down argument', Alice objected.

- When I use a word, Humpty Dumpty said, in rather a scornful tone, it means just what I choose it to mean - neither more nor less. 
- The question is, said Alice, whether you can make words mean so many different things.

- The question is, said Humpty Dumpty, which is to be master that's all.

Questions of power and legitimacy are often relevant in medical scientific discussions. Think, for instance, of the recurring discussions about whether or not the power of pharmaceutical companies influences the production of clinical knowledge. For instance, it was recently reported in The Journal of American Medical Association (May 17, 2006) that concerning vascular diseases, clinical trials funded by profit based organizations appeared more likely to report positive findings than those funded by non-profit organizations. Such facts, however, are quite compatible with the fact that medical research has a truly epistemological and logical side to it too. Some arguments in science have to be allowed to be arguments ad hominem, but all arguments cannot be allowed to be of this kind.

There are also negative ad hominem arguments. They claim that a certain view is false since it is defended by a person that is regarded as being a bit crazy, belonging to some enemy camp, or as simply benefiting from putting forward such a view.

\subsection{Deductive and inductive inferences}

Some arguments are able to show that from views already accepted as true, one can infer that, necessarily, a certain other view is true, too. In such cases, the argumentative link is a deductive inference. In the other kind of inferences that we shall discuss in this section, e.g., inductive inferences, there is no similar necessity to be found between premises and conclusions (this kind of induction has, note, nothing to do with 'mathematical induction', not to speak of 'electromagnetic induction', 'enzyme induction' and 'immunological induction'). If two persons share some premises but differ with respect to a conclusion that follows deductively, then at least one of them is in serious argumentative trouble; if the conclusion follows only inductively, this need not be the case.

In both deductive and inductive inferences, premises and conclusions are entities (beliefs, assertions, sentences, statements, propositions) that can be 
ascribed a truth-value, i.e., they can be regarded as being true or false, even though their actual truth-value in fact makes no difference to the validity of the inference in question. Inferences that are presumed to be deductive inferences but are not, are often called invalid deductions. A very simple (valid) deductive inference is:

premise 1: if there are red spots all over the body, then there is the measles

premise 2: $\quad$ there are red spots all over the body

hence:

conclusion: there is the measles

No physician would admit the first premise to be true without qualifications, but this is beside the point at issue. A deduction is characterized by the fact that, necessarily, if the premises are true then the conclusion is true, too. A deduction is truth-transferring and truthpreserving, but not truth-guaranteeing. If there is no truth to transfer and preserve, the truth of the conclusion cannot be guaranteed. Deductions tell us neither (a) whether the premises are true or false, nor (b) whether the conclusion is true or false when the premises are false. But they tell us (c) that the premises cannot be true and the conclusion false. Here comes another deduction:

premise 1: if there are red spots all over the body, then there is cancer

premise 2: there are red spots all over the body

hence:

conclusion: there is cancer

These two deductive inferences acquire their truth-preserving power from the form of the assertions involved, not from the substantive content of the assertions. Both inferences have the same form. This can be seen in the following way. If we let $\mathrm{p}$ and $\mathrm{q}$ be variables for assertions (or 'propositions', as logicians prefer to say), the form of the examples can be represented by this schema: 
premise 1: $\quad$ if $\mathrm{p}$, then $\mathrm{q}$

premise 2: $\quad \mathrm{p}$

hence:

conclusion: $\mathrm{q}$

Whatever specific assertions we put in as values of $\mathrm{p}$ and $\mathrm{q}$ in this schema, it will be the case that the premises cannot be true and the conclusion false. Even though this schema does not contain any substantial semantic content, it is of course not completely semantically empty. First, the variables are variables only for entities that can be true or false; second, there is the semantic content of the expression 'if ... then'; third, since we have premise 1 and premise 2, there is also the semantic content of this implicitly present 'and'. Expressions such as 'if ... then', 'and', 'not', 'all', 'some', etc. are called logical constants. To claim that the inference schema above represents a deductive inference is equivalent to claim that the statement below is true:

- necessarily, if [(if p then q) and p], then q.

The statement 'if [(if p then q) and p], then q' is one of several formallogical truths. It - and the corresponding inference schema earlier presented - is since medieval scholasticism called 'modus ponens'. Another famous deductive inference schema is called 'modus tollens':

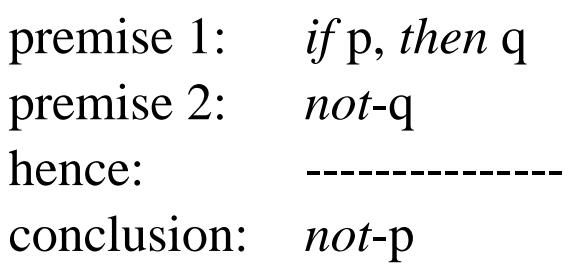

This form can be exemplified by: 
premise 1: if there are red spots all over the body, then there is the measles

premise 2: it is not the case: there is the measles

hence:

conclusion: it is not the case: there are red spots all over the body

We would also like to present two schemas that do not represent deductive (nor inductive) inferences; we will make use of them later on. We call them (a) 'inverse modus ponens' and (b) 'implication-equivalence conflation', respectively:

(a)

premise: $\quad$ if $\mathrm{p}$, then $\mathrm{q}$

premise: $\quad \mathrm{q}$

hence:

conclusion: $\mathrm{q}$

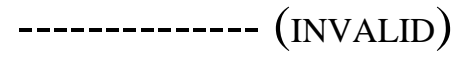

(b)

if $\mathrm{p}$, then $\mathrm{q}$

So far, we have presented parts of propositional logic, i.e., a logic where the variables in the inference schemas are variables for whole assertions. If a presumed inference is deductively valid in propositional logic, it is deductively valid - period. However, even if a presumed inference that is concerned with everyday assertions is invalid in propositional logic, it might nonetheless be valid in a logic that also takes the internal structure of the assertions/propositions at hand into account. Look at the following classic inference:

premise 1: $\quad$ all human beings are mortal

premise 2: $\quad$ Socrates is a human being

hence:

conclusion: Socrates is mortal

When this inference is formalized in propositional logic, we arrive at the invalid formal schema below (from two arbitrary assertions one cannot deduce a third arbitrary assertion): 


$\begin{array}{ll} & \text { propositional logic } \\ \text { premise 1: } & \mathrm{p} \\ \text { premise 2: } & \mathrm{q}(=\text { an assertion that may be distinct from } \mathrm{p}) \\ \text { hence: } & \text {-------------------------------------------- (INVALID)} \\ \text { conclusion: } & \mathrm{r}(=\text { an assertion that may be distinct from } \mathrm{p} \text { and } \mathrm{q})\end{array}$

However, if the same inference about Socrates is formalized in Aristotelian subject-predicate logic or term logic, we obtain the more fine-grained and valid formal schema below:

$\begin{array}{ll} & \text { Aristotelian } \\ \text { premise 1: } & \text { all H are M } \\ \text { premise 2: } & a \text { is } \mathrm{H} \\ \text { hence: } & \text {-------------- } \\ \text { conclusion: } & a \text { is } \mathrm{M}\end{array}$

In everyday life, we are not only following grammatical rules without noticing, we are also following many deductive inference rules without noticing. In the Socrates-is-mortal example, most people realize immediately that it follows from the premises that Socrates has to be mortal, but few are able to state explicitly that this is due only to the exemplified logical form. This fact of unconscious deductive inferences means, among other things, that in medical research there is usually no need to make simple deductions as those above explicit. Nonetheless, it is important for medical researchers to know explicitly what is characteristic of deductive inferences. The reason is that not only formal-logical derivations but also mathematical derivations are deductions, and mathematics plays a great role in modern medical science.

Even though purely mathematical truths such as ' $1+2=3$ ' and ' $7 \cdot 8=56$ ' and the corresponding inference rules seem to differ radically in form from formal-logical truths such as 'if [(if $p$ then $q$ ) and p], then q' and the corresponding inference rules, there is a certain similarity. Neither kind of assertions refers to anything in the world. It is impossible to point at something in the world and claim that it is simply ' 2 '; it has to be 2 of something, like ' 2 chairs', ' 2 cm', and so on. Some famous philosophers, in particular Gottlob Frege (1848-1925) and Bertrand Russell (1872-1970), 
have argued, appearances notwithstanding, that mathematical truths at bottom simply are formal-logical truths, but no consensus to this effect has emerged in the philosophical community. However, everyone agrees that if from some pure mathematical statements (premises) one can mathematically derive a certain conclusion, then (in two equivalent formulations):

- necessarily, if the premises are true, then the conclusion is true;

- not possibly, the premises are true, but the conclusion is false.

If someone claims that the premises of a certain mathematical inference are true, but that the conclusion is false, then he is as illogical as someone who denies a formal-logical deductive inference.

Let us now turn to inductive inferences. Even if an inductive inference has been made in the best possible way, it may nonetheless be the case that the premises are true but the conclusion false. This fact may easily be overlooked in empirical-statistical research when mathematical methods are used in the transition from descriptions of the sample (the premises) to stating some truth about the corresponding population (the conclusion); we will return to this below in Section 4.7.5.

In an inductive inference, the premises describe a number of (presumed or real) facts of a certain kind; normally, they are the results of a number of already made observations, e.g., 'some swans, namely the observed ones, are white'. The conclusion describes cases - of the same kind - that, to start with, were not regarded as facts. An inductive conclusion can describe either

(i) a single case of the kind under consideration

('the next swan will be white, too'),

(iia) a finite number of such cases

('all the swans in the zoo are white'), or

(iib) all cases of this kind whatsoever

('all swans are white').

In the last case we have a real (unlimited) generalization. In an inductive inference a step is taken either from some to the next of the same kind as in 
(i), or, more importantly in research, from some to all of the same kind as in (iia) and (iib). For instance, from the fact that all men so far (= some men) have died, I can try to infer inductively that (i) I will die, that (iia) all now living persons will die, and (iib) all men whatsoever will die. Let us now see how this reasoning can be applied to a medical example.

Assume that a clinician observes that his depressed male patients who are treated with SSRI (serotonin selective reuptake inhibitors) as a side effect are relieved also of another problem: premature ejaculation. Based on his observations (sample) he first draws the limited inductive inference (i) that the same will happen with his next patient, but later on he makes a true inductive generalization (iii) to the effect that SSRI always has a beneficial effect on men suffering from premature ejaculations. Schematically:

premise: some men, suffering from premature ejaculation, are cured by SSRI

hence:

conclusion: all men, suffering from premature ejaculations, will be cured by SSRI

This 'hence' of inductive generalizations can mean three different things, which, from an epistemological point of view, have to be kept distinct. We will use only the third one. First, 'hence' might mean only that the premise makes it reasonable to put forward the conclusion as a hypothesis that, in turn, ought later to be tested (e.g., by means of randomized controlled trials; see Chapter 6.3). Looked upon in this way, i.e., as being only hypotheses generators, inductive generalizations are of course epistemically unproblematic. Second, an inductive 'hence' might be read as saying that the truths of the premises are transferred to the conclusion. This reading should not at all be allowed, since there simply never is such a truth-transference; if there were, we would have a deductive inference.

Third, and reasonably, 'hence' might be interpreted as saying that the inductive inference schema makes - if the premises are true - the truth of the conclusion epistemically probable. Or, in other words, that the premises give inductive support to the conclusion, i.e.: 
- probably, if the premises are true, then the conclusion is true.

This understanding of induction is quite consistent with the fact that the premises might be true but the conclusion false. The epistemic probability mentioned take degrees, i.e., in particular cases it may be so small that the conclusion should not be considered. When the epistemic probability of the conclusion comes only from the forms of the inductive inference ('some to the next' or 'some to all') it is almost certainly too small to be of interest. In interesting inductions, some epistemic probability has in each concrete case to come also from intuitions connected to the substantive content displayed in the premises and the conclusion of the induction; here, socalled tacit knowledge (Chapter 5) may play a part.

The essence of induction in research is a transition from 'some of a certain kind' to 'all of the same kind'; in everyday life it is mostly a transition to 'the next of the same kind'. However, it is seldom a matter of only an immediate transition 'some $\rightarrow$ all', as when people in Europe once upon a time made an inference from 'some (all observed) swans are white' to 'all swans are white'. Mostly, there is a pre-existing 'all-premise' as well, and the skeleton of the inductive procedure had better be represented as: '(all $\rightarrow$ ) some $\rightarrow$ all'. In modern research, something takes place before the inductive transition from sample to population is made. The observations that ground the 'some-assertions' in question are not mere chance observations. Let us explain by means of a simple non-medical example. Assume that we want to make an inductive forecast about how people will vote in the next election. How should we proceed? Answer: the two arrows in the form 'all (1) $\rightarrow$ some (2) $\rightarrow$ all' ought broadly to look as follows:

1. based on our knowledge of how all citizens (population) in various regions, occupations, ages, and so on have voted in earlier elections, we try to find a group of some citizens (sample) that mirror the overall voting pattern; when this is done, we ask the persons in the sample how they will vote, whereby we obtain the facts that constitute the premises in our inductive inference; 
2. from these facts about how some citizens will vote, we inductively infer how all will vote.

Of epistemological importance is the fact that what step 2 concretely looks like is dependent on what step 1 looks like. At the same as one decides what the sample of the population should look like, one decides how one should return from the sample to the population. Therefore, to people who are taught only to make the second step, and to make it by means of mathematical formulas, it may falsely look as if they are simply deducing facts about the population (the conclusions) from the facts in the sample (the premises). The inductive inferences become hidden in the hypothesis that the sample is representative.

Most philosophers and many scientists living before 'the fallibilistic revolution' (Chapter 3 ) wanted and searched for certain and incontestable knowledge. To them, it was quite a problem that inductive inferences do not transfer truth from premises to conclusions; it was called 'the problem of induction'. Since this problem was first clearly stated by the Scottish philosopher David Hume (1711-1776), it is also called 'Hume's problem'. But already the so-called Ancient Skeptics of the Graeco-Roman culture had seen it.

Consider now, to end this section, the following inference:

premise 1: everyone suffering disease $\mathrm{D}$ is cured by treatment $\mathrm{T}$ premise 2: $\quad$ Paul is suffering disease $\mathrm{D}$ and has received treatment $\mathrm{T}$ hence:

conclusion: Paul will be cured

This inference is not an induction. It is a deduction. Nonetheless it is by no means certain that Paul will be cured. Why? Since the first premise is based on an inductive inference it might well be false; therefore, premise 1 contains no certain truth that can be transferred to the conclusion.

Whereas formal-logical and mathematical deductive inferences cannot possibly expand the empirical content of the premises, such an expansion is precisely the aim of inductive inferences. The remarkable fact is that empirical assertions, especially in the form of mathematically formulated laws, can have an empirical content that the speakers are not fully aware 
of. Therefore, even though deductive inferences cannot expand the empirical content of the premises, they can - and often do - expand the explicitly known such content. Formal-logical inferences cannot expand the content because their necessity relies only on the form of the premises; mathematical inferences cannot expand empirical content because they are concerned only with relations between space- and timeless numbers.

\subsection{Thought experiments and reductio ad absurdum arguments}

Aristotle (384-322 BC) is the first philosopher to realize that logical inferences ground their validity only in the form of the assertions made, and that therefore such inferences are valid independently of the truth of the premises. But he also noted another and related thing. Even when we make inductive inferences, and even when we put forward arguments ad hominem, we have to talk and think in conformity with the law of contradiction, i.e., in situations where we are interested in truth, we are not allowed to regard as true assertions that have the logical form of a contradiction. (The law is sometimes, and more adequately, also called 'the law of non-contradiction'.) In propositional logic, the basic form for a contradiction is 'p and not-p', an example being 'Jones has fever and it is not the case that he has fever'; in Aristotelian term logic, the basic form for a contradiction is ' $\mathrm{S}$ is $\mathrm{P}$ and not- $\mathrm{P}$ ', an example being 'Jones' body temperature is $39^{\circ} \mathrm{C}$ and $37^{\circ} \mathrm{C}$ '. All substantial assertions that fit into the logical forms ' $\mathrm{p}$ and not-p' and ' $\mathrm{S}$ is $\mathrm{P}$ and not-P' are necessarily false because of their logical form. To reject contradictions is a basic precondition for all form of rational argumentation, however weak the form is in other respects. To deny a valid deduction is to state a contradiction. Of course, when joking and when talking metaphorically, contradictions can make very good sense.

Allowing contradictions means leaving the realm of argumentation completely behind. The peculiar status of logical contradictions can be made visible as follows. Assume that someone wants to argue that logical contradictions in spite of all need not be false. Then, in relation to at least one contradiction ' $\mathrm{p}_{1}$ and not- $\mathrm{p}_{1}$ ' this person has not only to 
- maintain that ' $\mathrm{p}_{1}$ and not- $\mathrm{p}_{1}$ ' is true, he also has to

- deny that ' $\mathrm{p}_{1}$ and not- $\mathrm{p}_{1}$ ' is false.

That is, he has to take it for granted that ' $\mathrm{p}_{1}$ and not- $\mathrm{p}_{1}$ ' cannot be both true and false simultaneously. In his denial of the law of contradiction he has nonetheless to presuppose that the statement ' $\mathrm{p}_{1}$ and not- $\mathrm{p}_{1}$ ' conforms to the law of contradiction. The law has this feature: in order to question it one has to presuppose it. It can be neglected, but it can never be argued away. If one clinician says 'this patient has a lung infection', but another says 'no, he has not', and both think that there is no conflict, they have entered the realm of the absurd. If one physicist says without any hidden qualifications 'Newtonian mechanics is true', but another says 'no, the special relativity theory is true', and both think that there is no conflict, they have also entered the realm of the absurd. Note, however, that if the first physicist says 'Newtonian mechanics is false for velocities close to and above that of the velocity of light, but approximately true for lower velocities' then there is no contradiction or absurdity.

Now and then, both in science and philosophy, people make use of a line of argumentation that is termed 'reductio ad absurdum'. In such an argument, a seemingly reasonable view is shown to contain or imply, unexpectedly, a logical contradiction or some other kind of wholly unreasonable view. Since the first view (the premise, p) is 'reduced' to something absurd, it cannot be accepted. The whole argumentation with its 'reduction to the absurd' and the eventual rejection of the contested view (p) has the form of modus tollens:

premise 1: if $\mathrm{p}$, then $\mathrm{q}$

premise 2: not-q (since $\mathrm{q}$ is absurd; perhaps is in itself a contradiction)

hence:

conclusion: not-p

The reductio ad absurdum pattern is often part of thought experiments that are intended to show that a certain view must be false. Here comes a famous example from the history of physics, Galileo Galilei's arguments to 
the effect that the kinetic theories of his predecessors could not possibly be true.

According to the view of the causes of movements that Galilei criticized, heavy bodies fall faster than lighter ones. This presumed law of nature was apparently supported by many simple empirical observations. If we simultaneously drop a book (heavy thing) and a sheet of paper (light thing), the book reaches the floor before the paper. Therefore, according to this law, the following is true: 'a stone weighing $3 \mathrm{~kg}$ will fall with a velocity $\left(\mathrm{v}_{3}\right)$ that is higher than that of a stone of $2 \mathrm{~kg}\left(\mathrm{v}_{2}\right)$, and one of $2 \mathrm{~kg}$ will fall faster than one of $1 \mathrm{~kg}\left(\mathrm{v}_{1}\right)^{\prime}$ '. Let us now in thought connect a $2 \mathrm{~kg}$ stone to a $1 \mathrm{~kg}$ stone, and ask: 'How fast will this new stone fall?' Since it weighs $3 \mathrm{~kg}$, we can deduce from our premises that 'it will fall faster than a $2 \mathrm{~kg}$ stone' (p). However, since its $1 \mathrm{~kg}$ part will fall more slowly than the $2 \mathrm{~kg}$ part, the $1 \mathrm{~kg}$ part ought according to our premises slow down the speed of the $2 \mathrm{~kg}$ part, and so: 'the combined $3 \mathrm{~kg}$ stone will move slower than a 2 kg stone' (not-p).

$3 \mathrm{~kg}, \mathrm{v}_{3}$

$2 \mathrm{~kg}, \mathrm{v}_{2}<\mathrm{v}_{3}$

$1 \mathrm{~kg}, \mathrm{v}_{1}<\mathrm{v}_{2}$

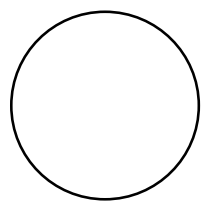

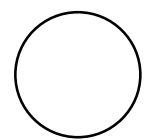

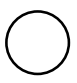

$(2+1) \mathrm{kg}, \mathrm{v}=$ ?

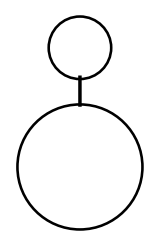

From the premises of the old theory $(=t)$, a contradiction (p and not-p) is deduced: a $3 \mathrm{~kg}$ body falls both more rapidly and more slowly than a $2 \mathrm{~kg}$ body. We have the inference schema:

premise 1: if $\mathrm{t}$, then ( $\mathrm{p}$ and not-p)

premise 2: $\quad$ not- (p and not-p)

hence:

conclusion: not-t

According to the argument, the old kinetics has to be regarded as false and, consequently, it ought to be abandoned or at least revised. Galilei's own alternative successful hypothesis was that all the four bodies mentioned, quite independently of their weight, fall at the same speed - but 
only in a vacuum. A sheet of paper falls more slowly to the ground than a book because the air resistance functions differently in the two cases; it becomes greater on the sheet of paper.

\subsection{Hypothetico-deductive arguments}

The next argumentative pattern will be called 'hypothetico-deductive arguments'. In twentieth century philosophy of science, there was much talk about the hypothetico-deductive method. Famously, in their search for a unified science the logical positivists (Chapter 3.4) hailed it as the method of science. By now, however, it is quite clear that it is merely one of several kinds of methods or argumentative patterns within the sciences. In itself, the hypothetico-deductive method is neither a sufficient nor a necessary condition for calling an investigation or argumentation scientific. Its name does not contain the term 'inductive', but, as we will make clear during the exposition, hypothetico-deductive arguments/inferences can, just like inductive inferences, supply no more than inductive support for the hypotheses and generalizations under consideration.

In order to make the presentation simple, we will take our main illustrative example from proto-science. We want to display a simple abstract pattern, but one that in more complicated and hidden forms exist also in real modern science. It is in principle easy to implement numerically formulated laws in the schemas below. Assume that (living long ago) we have suddenly noticed that some metal pieces expand when heated. If we are old-fashioned inductivists, we might then reason as follows:

premise: $\quad$ when heated, these (some) pieces of metal expand hence:

conclusion: when heated, all pieces of metal expand

If, instead, we want to use a hypothetico-deductive argument, we shall start with what is above the end point, the conclusion. In this kind of argument, one always starts with a general hypothesis. Normally, such a hypothesis is based on some observations, but from the point of view of the argument itself, it is completely uninteresting what has made the hypothesis arise in someone's mind. The point is how to test it, and such a test has three steps. 
In the first step, from the general hypothesis and descriptions of some spatiotemporally specific initial conditions we deduce a test implication (for the hypothesis). Since the law has a conditional form, if heating then expanding, the categorically formulated so-called initial conditions are needed in order to come in contact with a determinate portion of reality. When the law has numerical variables, the initial conditions assign values to the variables, but here comes the proto-scientific example:

hypothesis: $\quad$ when heated, all pieces of metal expand

initial conditions: these (some) pieces of metal are heated

hence:

test implication: these (some) pieces of metal expand

According to deductive logic (modus ponens), if the premises (the general hypothesis and the initial conditions) are true, then the test implication is true too. But is the test implication true? Answer: we cannot know. Even if we take it for granted that the premises constituted by the initial conditions are absolutely true, we cannot know that the test implication is true since, by definition, it is partly derived from a hypothesis. Whether the test implication is true or false has to be tested empirically and independently of the inference displayed; this is of course the reason why it is called a 'test implication' (for the hypothesis).

The second step of the test consists in trying to find out whether the test implication is true or not; the third step in finding out what conclusion we can then draw with respect to the truth-value of the hypothesis itself. Let us first investigate the third step on the assumption that the second step has made us believe that the test implication is true. In a way, but with a difference, we are now back in the inductive situation described in Section 4.3. Since we want to say something about the truth of the general hypothesis, we have the following schema (where the premises are taken to be true): 
initial conditions: these (some) pieces of metal are heated

test implication: these (some) pieces of metal expand

hence:

hypothesis: $\quad$ when heated, all pieces of metal expand

This schema does not represent any deductive inference; here, the truth of the premises is not transferred to the hypothesis. They only give inductive support.

Out of context, the conjunction of the two premises is equivalent to the single premise in the inductive inference described at the beginning of this section: 'when heated, these (some) pieces of metal expand'. However, the contexts make them differ. The premise of the pure inductive inference is only backward-looking, i.e., people doing pure inductive inferences are only relying on what they have already got, but the second premise of the last schema was once a matter of prediction. That is, the hypotheticodeductive procedure contains a stage where one consciously has to search for new observations. This might seem a negligible difference, but from a methodological point of view it is not. We are quite prone to see what we would like to see, and most scientists are somewhat anxious that their hypotheses may turn out to be false. Therefore, it is important to make some careful new observations even when one's hypothesis has been created on the basis of quite accurate old observations.

Another important difference between inductive arguments and hypothetico-deductive arguments is that only the latter can give inductive support to hypotheses about unobservable entities. Many sciences are preoccupied with things and properties that are not directly observable, but no inductive argument can take us from observables to unobservables since the premises and the conclusions have to talk about entities of the same kind. The hypothetico-deductive method contains no such constraint. It allows the introduction of hypotheses about unobservables on the requirement that test implications about observables can nonetheless be deduced. The hypotheses about the proton, the electron, and the neutron are classical examples.

In order to make the ensuing presentation brief, we need to increase the level of abstraction. If ' $\mathrm{H}$ ' is a variable for hypotheses, ' $\mathrm{I}$ ' a variable for 
initial conditions, and ' $\mathrm{T}$ ' for test implications, then the hypotheticodeductive schema can be presented either as in (a) or as in (b) below:

(a)

$\begin{aligned} & \mathrm{H} \\ \text { hence: } & \mathrm{I} \\ & ----\end{aligned}$

$\mathrm{T}$ (b)

necessarily, if ( $\mathrm{H}$ and $\mathrm{I})$ then $\mathrm{T}$

We can now abstractly examine what happens both when $\mathrm{T}$ for empirical reasons is true and when it is false. To start with, we assume that I (= the conjunction of the initial conditions) is beyond reasonable doubt true. Then, if $\mathrm{T}$ (our test implication) is false, for reasons of deductive logic we have to conclude that $\mathrm{H}$ (our hypothesis) is false, too. The inference can be presented as a simple case of modus tollens if the initial conditions (which are assumed to be true) are left out of account:

$\begin{array}{ll}\text { premise 1: } & \text { if } \mathrm{H}, \text { then } \mathrm{T} \\ \text { premise 2: } & \text { not- } \mathrm{T} \\ \text { hence: } & \text {--------------- } \\ \text { conclusion: } & \text { not-H }\end{array}$

In this situation, we can truly say that the test implication falsifies the hypothesis. What then to say about the case when $\mathrm{T}$ is true?

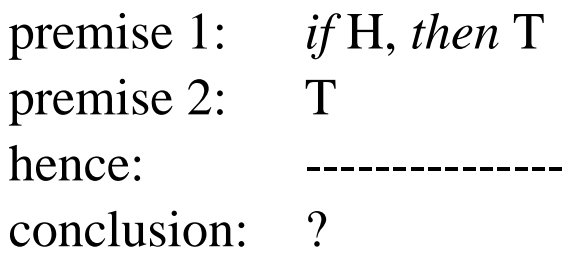

This is an abstract form of the metal-expands-when-heated case already discussed. That is, deduction cannot here tell us whether $\mathrm{H}$ is true or false. From the truth only of the premises we cannot deduce anything about the truth or falsity of $\mathrm{H}$ (the schema is a case of the invalid inverse modus ponens). Briefly put: the fact that a hypothesis is not falsified by a certain test does not imply that it is true. 
If the truth-values of the initial conditions and the test implication are easy to determine, then there is a logical asymmetry between the verification and the falsification of a hypothesis. On the assumptions stated, a true generalization (one not confined to a finite number of cases) might be falsified but never verified. However, the methodological importance of this logical asymmetry becomes almost negligible when the complications of real research are taken into account. In actual science, it is hardly ever the case that test implications can be deduced only from the hypothesis under consideration and some relevant initial conditions. Many auxiliary hypotheses are also needed. In order to make our abstract hypothetico-deductive schema come a bit closer to real research, it has to be expanded into the one below $\left(\mathrm{H}_{\mathrm{An}}\right.$ is short for 'auxiliary hypothesis number $n$ ' and $I_{A n}$ is short for 'initial conditions for auxiliary hypothesis number n'):

\begin{tabular}{|c|c|}
\hline $\begin{array}{l}\text { hypotheses: } \\
\text { initial conditions: } \\
\text { hence: }\end{array}$ & $\begin{array}{l}\mathrm{H} \text { and } \mathrm{H}_{\mathrm{A} 1} \text { and } \mathrm{H}_{\mathrm{A} 2} \text { and } \mathrm{H}_{\mathrm{A} 3} \text { and } \ldots \mathrm{H}_{\mathrm{An}} \\
\mathrm{I} \text { and } \mathrm{I}_{\mathrm{A} 1} \text { and } \mathrm{I}_{\mathrm{A} 2} \text { and } \mathrm{I}_{\mathrm{A} 3} \text { and } \ldots \mathrm{I}_{\mathrm{An}}\end{array}$ \\
\hline & \\
\hline
\end{tabular}

If this $\mathrm{T}$ is false (and, again, all the initial conditions are true), it follows deductively only that the whole conjunction ' $\mathrm{H}$ and $\mathrm{H}_{\mathrm{A} 1}$ and $\mathrm{H}_{\mathrm{A} 2}$ and $\mathrm{H}_{\mathrm{A} 3}$ and ... $\mathrm{H}_{\mathrm{An}}$ ' has to be false; and so it is as soon as only one of these Hs is false. Why, we might ask with good reasons, blame $H$ when there are $n$ auxiliary hypotheses that can be blamed too? As the hypothetico-deductive method is traditionally described, it contains no method of choice for this kind of situation. And, from our presentation of the concept of paradigms (Chapter 2.4), it follows that there can be no simple such method.

In some cases, even the last and complex hypothetico-deductive schema has to be made more complex. Assume that we want to test the hypothesis that metals expand when heated, and that we have a simple case with no auxiliary hypotheses and no doubtful initial conditions: 
hypothesis: $\quad$ always, if a piece of metal is heated, then it expands

initial condition: this piece of metal is heated

hence:

test implication: this piece of metal expands

Assume now that the heated piece of metal referred to is situated in a clamping device that does not permit it to expand. That is, the metal piece is heated but it does not expand. The test implication is false and the initial condition is true, but is the hypothesis thereby falsified? If the schema captures the whole of the experimental situation then, for deductive reasons, the hypothesis has to be regarded as false. But this seems odd. Better is to interpret the hypothesis as saying 'always, if a piece of metal is heated, it has a tendency to expand'. The absence of expansion can then be explained as being due to the counteracting forces of the clamping device. There exists, as predicted, a tendency, but it cannot be realized because of counteracting tendencies.

Assume that you have two conflicting desires. For instance, you want to sit down in order to read a book, but you would also like to take a walk. In this situation, your two behavioral tendencies may for a while counteract each other in such a way that you just stand still; and this in spite of the fact that you have no rock-bottom wish to stand still. In the way now explained, tendencies can exist unrealized in both persons and inanimate nature. Hypotheses that predict such tendencies to arise can only be proven false under a very special assumption. One that claims: no other factors than those stated in the auxiliary hypotheses $\left(\mathrm{H}_{\mathrm{An}}\right)$ can here make counteracting or reinforcing tendencies arise. Such an assumption is not an ordinary generalization, since it has not the form 'all A are B'; nor is it an initial condition for an auxiliary hypothesis $\left(\mathrm{I}_{\mathrm{An}}\right)$, since it has not the form 'this is A' or 'this is B'. It has been called both 'provisoe' and 'closure clause', and it has the form 'there are no more relevant factors in the situation at hand'. That such an auxiliary clause is true is in many cases just as uncertain as the hypothesis and the auxiliary hypotheses on trial.

In Newtonian mechanics, the need for provisoes is more easily seen than in most other theories. Apart from the three laws of motion and the law of gravitation, this theory contains an explicit superposition principle for 
forces; it says that when making a calculation or an experiment, then all forces at play have to be added. But since the principle does not tell how many forces there are, one has on each and every occasion to 'close it' by means of an auxiliary (closure) clause that says: 'no more forces are relevant'.

Normally, when there is talk about unobservable entities in science, one refers to entities that are either too small (sub-molecular entities) or too far away (extremely distant galaxies) to be able to be observed through microscopes or telescopes, respectively. In the same way, tendencies that exist unrealized in inanimate nature are also unobservable, but for another reason, namely that they can exist unrealized.

Tendencies are posited in the medical sciences too. Let us give three examples. First, the disorder thrombophila is normally defined as a disorder of the hemopoietic system in which there is an increased tendency for forming thrombi. Second, there is research around the question whether some people may have inborn or acquired psychopathic tendencies. Third, there are good reasons to speak of people's tendencies to react on a certain medical treatment. On one patient a treatment may have a considerable effect but on another none. And this difference may be due to the fact that the latter patient is in a situation where the tendency created by the treatment is counteracted by some other tendency.

The existence of tendencies can explain why a certain treatment might trigger a specific reaction in some patients, but leave others unaffected. Therefore, many medical tests and predictions may require, just like predictions with Newtonian mechanics, an auxiliary assumption to the effect that nothing in the situation at hand counteracts or reinforces the tendency described by the main hypothesis $(\mathrm{H})$. In cases involving tendencies, the abstract hypothetico-deductive schema looks as follows:

hypothesis: $\quad \mathrm{H}$

auxiliary hypotheses: $\quad \mathrm{H}_{\mathrm{A} 1}, \mathrm{H}_{\mathrm{A} 2}, \mathrm{H}_{\mathrm{A} 3}, \ldots \mathrm{H}_{\mathrm{An}}$

initial conditions: $\quad \mathrm{I}, \mathrm{I}_{\mathrm{A} 1}, \mathrm{I}_{\mathrm{A} 2}, \mathrm{I}_{\mathrm{A} 3}, \ldots \mathrm{I}_{\mathrm{An}}$

closure clause:

no other auxiliary hypotheses are relevant

hence:

test implication: 
If $\mathrm{T}$ is true, then everything that is above the inference may be true too, but it need not be. If $\mathrm{T}$ is false, then for formal-logical reasons something above the inference line has to be false too. But what? There is much to choose between. To make the best choice may require long scientific training, in some cases even a grain of genius. Neither in its original verificationist form nor in its later falsificationist variety (see presentation of Popper in Chapter 3.5) can a hypothetico-deductive argument supply more than inductive support for the hypothesis under test. As we can never be certain that we have verified a theory, we can never be certain that we have falsified it. But we can receive positive and negative empirical evidence, i.e., positive and negative inductive support. Theories are always empirically underdetermined, but seldom completely empirically vacuous.

The general hypothetico-deductive form of argumentation now presented is given a specific form in the randomized controlled trials of medical science; we present it in Chapter 6.3.

\subsection{Arguments from simplicity, beauty, and analogy}

Even when brought together in hypothetico-deductive arguments, deductive and inductive arguments cannot supply a conclusive verdict on the truth or falsity of empirical hypotheses and theories. This empirical underdetermination implies fallibilism, but not epistemological relativism or social constructivism. Why? Because it admits that nature can make some test implications false and thereby tell us that something is wrong. However, this underdetermination explains why scientists sometimes have recourse to arguments from simplicity, beauty, and analogy.

Ernest Rutherford (1871-1937), famous for putting forward the hypothesis that atoms contain electrons that orbit around a central nucleus (the proton), said: "Considering the evidence as a whole, it seems simplest to suppose that the atom contains a central charge distributed through a very small volume" (Hanson p. 216). Such considerations can be viewed as a way of making the invalid inverse modus ponens schema a bit more reasonable. Let $\mathrm{T}$ represent a description of all the evidence assembled (the test implications found to be true), and let $\mathrm{H}$ represent the hypothesis in question. If we leave auxiliary assumptions aside, we arrive at this deductively invalid inference schema: 
premise 1: if $\mathrm{H}$, then $\mathrm{T}$

premise 2: $\mathrm{T}$

hence: (INVALID)

conclusion: $\mathrm{H}$

Rutherford can be said to have used the next also deductively invalid but more reasonable schema:

premise 1: if $\mathrm{H}$, then $\mathrm{T}$

premise 2: $\mathrm{T}$

premise 3: $\quad \mathrm{H}$ is simpler than the alternatives

hence:

(INVALID)

conclusion: $\mathrm{H}$

In our opinion, such arguments can be allowed to play some role in the short run of research, but in order to be strong they have to be connected to some overarching principle that says 'nature is simple'. But this creates a new problem: how is such an overarching principle to be epistemologically justified? Because of this predicament, we will only say a few words about what scientists can mean when they speak of simplicity, beauty, and analogies.

In physics, Maxwell's equations, which describe how properties of electromagnetic waves are related to electric charges and currents, are often described as beautiful, over-archingly symmetrical, and simple. They look as follows:

$$
\begin{aligned}
& \text { Maxwell's equations: } \\
& \hline \nabla \cdot \mathrm{D}=\rho \\
& \nabla \cdot \mathrm{B}=0 \\
& \nabla \times \mathrm{E}=-\partial \mathrm{B} / \partial \mathrm{t} \\
& \nabla \times \mathrm{H}=\mathrm{J}+\partial \mathrm{D} / \partial \mathrm{t}
\end{aligned}
$$

We agree; there is something appealing in this symbolism even if one does not understand it exactly and, therefore, cannot see its simplicity against the background of the complexity of the reality described. 
Sometimes even beauty is given the role that simplicity has above. In such cases we obtain this inference schema:

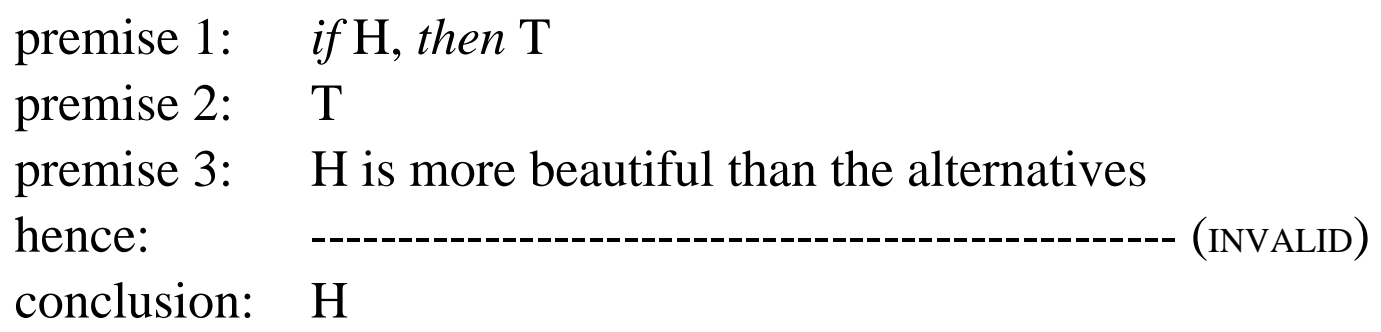

In the discovery of the DNA molecule, several famous researchers seem to have thought of their discoveries in terms of beauty; often being beautiful means being symmetric. "What a beautiful molecule!", was the reaction of Rosalind Franklin (1920-1958) when she was the first person to observe the DNA molecule from an X-ray diffraction picture. J. D. Watson (b. 1928) characterized Linus Pauling's discovery of the structure of proteins as 'unique and beautiful'. Although they were competitors in the discovery-of-the-DNA race, Linus Pauling had inspired 'the winners' Watson and Francis Crick (1916-2004) both in their puzzle-solving strategy and in their research outlook: the truth should be recognized as simple, straightforward, and beautiful. Watson and Crick succeeded, and most people seem to find the outlines of double helix model beautiful (see Figure 1).

Figure 1: The DNA model.

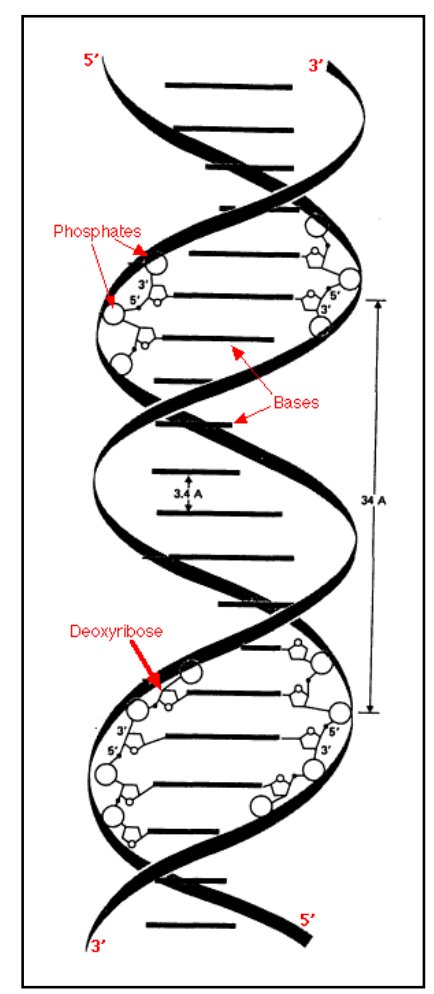


Let us now turn to arguments from analogy. To say that $A$ and $B$ are analogous is sometimes just to say that they are similar, but often something more complex is meant, namely that 'As are to $C$ s what $B$ s are to Ds'. To claim that handlebars are analogous to rudders is to claim that handlebars $(A)$ are to bicycles $(C)$ what rudders $(B)$ are to ships $(D)$. We will start with simple similarity. Once again, we will quote from Alice in Wonderland - 'A Mad Tea-party'.

- I’m glad they've begun asking riddles. I believe I can guess that, said Alice aloud.

- Do you mean that you think you can find out the answer to it? said the March Hare.

- Exactly so, said Alice.

- Then you should say what you mean, the March Hare went on.

- I do, Alice hastily replied; at least - at least I mean what I say that's the same thing, you know.

- Not the same thing a bit! said the Hatter. You might just as well say that 'I see what I eat' is the same thing as 'I eat what I see!

- You might just as well say, added the March Hare, that 'I like what I get' is the same thing as 'I get what I like'!

- You might just as well say, added the Dormouse, who seemed to be talking in his sleep, that 'I breathe when I sleep' is the same thing as 'I sleep when I breathe'!'

Alice maintains that 'I say what I mean' is synonymous or equivalent to 'I mean what I say':

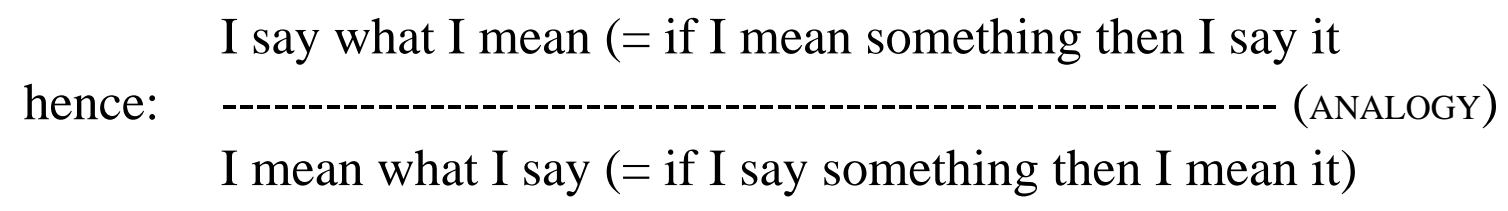

Her friends then retort that to make such a claim is as odd as to argue as follows: 


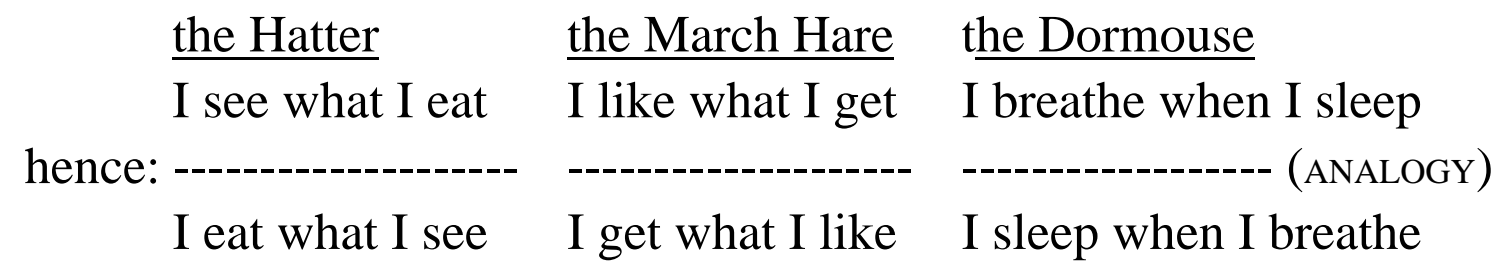

All these arguments can in propositional logic be given the invalid form of 'implication-equivalence conflation' (premises: 'if I eat something (p) then I see it (q)', 'if I get something then I like it', 'if I sleep then I breathe', respectively):

$$
\begin{array}{ll}
\text { premise: } & \text { if } \mathrm{p} \text {, then } \mathrm{q} \\
\text { hence: } & ----------- \text { (INVALID) } \\
\text { conclusion: } & \text { if } \mathrm{q} \text {, then } \mathrm{p}
\end{array}
$$

This invalid inference might be strengthened by adding an analogy premise; this premise adds something, but it does not make the inference deductively valid.

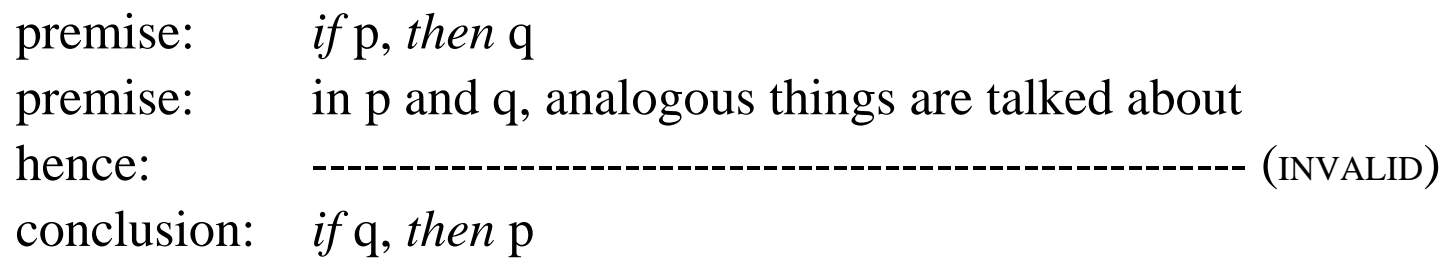

In the cases of Alice and her friends, however, there is no similarity between what is talked about in p (in turn: saying, seeing, liking, and breathing) and in q (in turn: meaning, eating, getting, and sleeping). There is only a similarity between the forms 'if $p$ then q' and 'if q then p'. Let us now look at the following inference schema (from $X$ to $A$ ):

there are $X$ s that are to $C$ s what $B$ s are to $D$ s hence: (ANALOGY)

As are to $C$ s what $B$ s are to $D$ s 
A good example of this schema is related to Darwin's discoveries; it looks as follows:

there is something $(X)$ that is

to the development of wild animals $(C)$

what breeding $(B)$ is

to the development of domestic animals $(D)$

hence: (ANALOGY)

natural selection $(A)$ is to $C$ what $B$ is to $D$

Questions such as 'What $(X)$ is to the foot $(C)$, what the palm $(B)$ is to the hand $(D)$ ?' are sometimes used to test the intellectual development of children. It is an intellectual achievement to be able to recognize similarities such as these. But, of course, as human beings we are also able to project onto the world resemblances that are not there. However, after the fallibilistic revolution one can well let arguments by analogy play some role in the context of justification as well as in the context of discovery. What role they will come to play in computer science is at the moment hard to tell, but since many decades there are in AI analogy-finding programs.

When we mentioned Pasteur's discovery that bacteria can cause infections (Chapter 2.4), we also mentioned that part of the process that led to this discovery was Pasteur's earlier discovery that yeast cells are not an accidental product of fermentation processes but the cause of them. In analogy with this reversal, he reversed also the view that microorganisms in infected wounds are accidental by-products into the view that, in fact, they cause the infection. We can now see the structure of the argumentation more clearly:

there is something $(X)$ that is to infections $(C)$

what yeast cells $(B)$ are to fermentations $(D)$

hence: (ANALOGY)

bacteria $(A)$ are to $C$ s what $B$ s are to $D s$

We will end this section with a little story; be it a myth or not. The surgeon who started to treat burn injuries with cold water discovered the 
treatment by means of an analogical inference made when he had breakfast. (Prior to this discovery, one avoided to pour water on burn injuries in order to minimize the risks of infection.) His wife normally served him a soft-boiled egg. One morning, however, she forgot to rinse the cooked hot egg in cold water. A few minutes later, when the surgeon started to eat the egg, it was hard. He asked his wife why the egg was hardboiled, and she explained what had happened. On a little reflection, the surgeon came to the conclusion that cold-water cooling of eggs inhibits an ongoing coagulation process that is caused by the heat from the boiling water. Further reflections, made him quickly believe that cold water can inhibit coagulation processes in all albumins. Then, thirdly, by means of an analogical inference he reached the conclusion that what cold water is to egg coagulation is probably to blood coagulation too. The form of this inference is a bit simpler than the earlier one, for it has the form: what $A$ is to $C$, must be to $D$ as well.

\subsection{Abductive reasoning and inferences to the best explanation}

In deductions, one is moving from premises to conclusions in such a way that if the premises are true then the truth of the conclusions is guaranteed. In pure inductions and in hypothetico-deductive arguments, not to speak of arguments from simplicity, beauty, or analogy, this is not the case. Here, true premises can only make the conclusion more or less epistemically probable. This is true also of the next kind of reasoning to be presented: abduction. What we have already said about the formal inference schemas for induction can now be repeated for abduction: some epistemic probability has in each concrete case to come also from intuitions connected to the substantive content displayed in the premises and the conclusion; here, so-called tacit knowledge (Chapter 5) may play a part. Other names for this kind of reasoning are 'retroduction' and 'inference to the best explanation'.

In our exposition of abduction, we will develop thoughts from C. S. Peirce and N. R. Hanson. We will distinguish two forms of abduction: 
- abduction to a known kind

- abduction to an unknown kind.

The inference schema for abduction to a known kind has, in Aristotelian term logic, a formal structure distinct from, but similar to, schemas for deductions and inductive generalizations that involve the same three sentences:

\begin{tabular}{|c|c|c|c|}
\hline & $\underline{\text { Deduction }}$ & Induction & Abduction \\
\hline prem & all $\mathrm{D}$ are $\mathrm{S}$ & $a$ is $\mathrm{D}$ & all $\mathrm{D}$ are $\mathrm{S}$ \\
\hline remise 2: & $a$ is $\mathrm{D}$ & $a$ is $\mathrm{S}$ & $a$ is $\mathrm{S}$ \\
\hline no & $a$ is $S$ & all $\mathrm{D}$ are $\mathrm{S}$ & $a$ is D \\
\hline
\end{tabular}

This form of abductive reasoning has the deductively invalid form that we have called 'inverse modus ponens'. This means that abductions rely for their kind of validity on the particular content of each case, not on the general form displayed above. Even if the very concept of abduction is unknown to clinicians, abductions play a large role in their life. The inference schema below exemplifies the form for abduction above (note that logic has to abstract away differences between verbs such as 'is' and 'have'):

premise 1: $\quad$ all persons having disease $\mathrm{D}$ have symptoms $\mathrm{S}$

premise 2: $\quad$ patient $a$ has symptoms $\mathrm{S}$

hence: (ABDUCTION)

conclusion: patient $a$ has disease $\mathrm{D}$

Even if patient $a$ has all the symptoms S of D, he may not suffer from D. To make a diagnosis is not to make a deductive inference; nor is it to make an inductive generalization. It is to make an abduction. In order to be able to make such inferences, clinicians need practical experience or what has been labeled 'tacit knowledge', but now we merely want to show that its formal structure is distinct from those of deduction and induction. The schema above explains why abduction is also called 'retroduction' and 'inference to the best explanation'. When a clinician diagnoses someone 
(a) as having a disease (D), he argues 'backwards' from the symptoms (the effects) to the disease (the cause), i.e., from the symptoms he does not deduce the fact that there is a disease, he retroduces it. Based both on the disease-symptoms generalization and his practical skills, he makes 'an inference to (what he thinks is) the best explanation' of the symptoms in the case at hand.

As an example of abduction to an unknown kind, we will use what both Peirce and Hanson thought of as "the greatest piece of Retroductive reasoning ever performed (Hanson p. 85, Peirce p. 156)”, namely Johannes Kepler's discovery that the planets do not have circular but elliptical orbits. When one already knows that all planets move in ellipses, one can deduce that a certain planet moves in an ellipse:

premise 1: $\quad$ all planets move in ellipses (all $\mathrm{D}$ are $\mathrm{S}$ )

premise 2: Mars is a planet ( $a$ is S)

hence:

conclusion: Mars moves in an ellipse ( $a$ is D)

When one knows only that some (say, three) planets move in ellipses, one can try the following inductive inference:

premise 1: these three bodies are planets $\quad(a, b, c$ are $\mathrm{D})$

premise 2: $\quad$ these three bodies move in ellipses $(a, b, c$ are $\mathrm{S}$ )

hence: $\quad$----------------------------------------- (INDUCTION)

conclusion: all planets moves in ellipses $\quad$ (all D are S)

Kepler could, when he started his work, make none of these inferences; nor the kind of abduction we have already presented. Why? In all these schemas the concept of an elliptical orbit figures in one of the premises, but neither Kepler nor anyone else had then entertained the idea that planets may move in ellipses. Rather, Kepler's way to the conclusion 'all planets move in ellipses' should be seen as consisting of the following two steps, the first being the truly abductive step: 


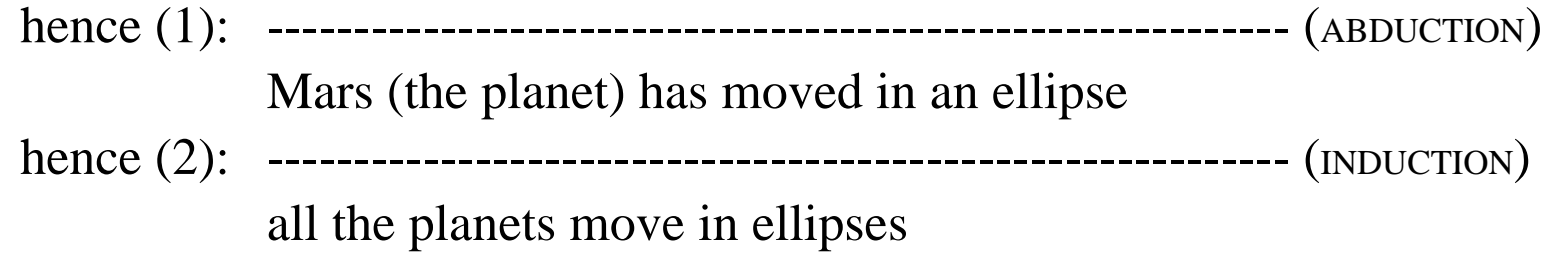

The second step came for Kepler automatically, since he simply took it for granted that he investigated Mars as a representative for all the six planets then known. Otherwise, this step has to take the form of an inductive generalization from one or some planets to all planets. Let us focus on the first step.

Mars' orbit is not directly observable from the earth. At the times of Kepler, the astronomers related the places the planets occupied at different times to the stars as seen from the earth. Since the earth itself moves, it is no simple task to extract from such 'inside' representations the corresponding orbits as (let us say) seen from most places outside the solar system. But things were even harder. Kepler had to free his mind from the view that - of course - planets move around one centre; ellipses have two. Therefore, it was quite a feat to be able to abduct ellipses from the data available. The most prominent astronomer at the time, Tycho Brahe (15461601), for whom Kepler worked as an assistant a short time, and whose data Kepler could use, was not able to do it. Before Kepler no one seems to have even suspected that the planets could be moving in ellipses.

Abductions to an unknown kind have quite a place in the history of medicine. Often, the discovery of distinct diseases such as Alzheimer's and Parkinson's has consisted in an abduction from symptom data to a disease. For example, what Brahe's data was for Kepler in relation to the elliptic orbit of Mars, the symptoms of Alzheimer's disease was for Emil Kraepelin (1856-1926) in relation to the disease as such. This is abduction at the observational level. To find unobservable causes of diseases already observationally identified, a second abduction is needed. In relation to Alzheimer's disease, this work was done by the man after whom the disease is now named, Aloysius Alzheimer (1864-1915).

In connection with abduction, some words about so-called ex juvantibus treatments and diagnoses are needed, too. 
According to some medical norms, physicians are always supposed to present a specific diagnosis before they start a treatment, but this is simply not always possible. Here is an example. According to the theory of deficiency diseases, a treatment with the relevant deficient substance will cure a patient. Let us take the case of iron deficiency based anemia. Sometimes a patient suffering from anemia has to be treated before it can be established what specific kind of anemia he has. If then, the anemia patient is treated with iron just provisionally, i.e., ex juvantibus, this choice of treatment does not deserve the name abduction. However, if in fact the patient becomes cured, and the physician therefore in retrospect makes the diagnosis that the patient actually suffered from iron-deficiency anemia, then this ex-juvantibus-treatment-based diagnosis is an abduction (to a known kind). Schematically:

premise 1: if patients with iron deficiency anemia are treated with iron, they will be cured

premise 2: this patient had anemia, was treated with iron, and was cured

hence: (ABDUCTION)

conclusion: this patient suffered from iron deficiency based anemia

Our general points about abduction in relation to medical science can be put as follows:

(a) all the first physicians to see true disease patterns (where others saw only disconnected illnesses or symptoms) made abductions to unknown (disease) kinds;

(b) all the physicians who every working day (based on some known disease-symptom correlation) diagnose patients as having known diseases are making abductions to known (disease) kinds.

\subsection{Probabilistic inferences}

Due to considerations of many different kinds - metaphysical (see Chapter 2), logical (see the sections above), technological (all measuring devices are somewhat uncertain), and ethical (see Chapters 9 and 10) - it is impossible in medical research to control all the factors that affect the outcomes of laboratory experiments, clinical research, and epidemiological 
investigations. Therefore, normally medical researchers have to talk in terms of probabilities when they present their results, be it that a certain disease or illness has a specific cause, that a certain treatment has a good effect, or that a certain kind of situation or habit contains a high risk for a disease. This fact, in turn, makes it important for everyone interested in medicine to have some understanding of some of the features that are specific to probability statements and to probabilistic inferences. Especially for clinicians, it is good to become aware of the complexity that surrounds probabilities for singular cases.

\subsubsection{Four kinds of probabilistic inferences and four kinds of probability statements}

For the philosophical-scientific purposes of this book, four kinds of probabilistic inferences and four kinds of probability statements have to be kept distinct. A probabilistic inference is an inference that involves at least one probability statement. Most of such inferences conform to the patterns of deduction, induction, and abduction already distinguished, but there are also other some patterns that have to be presented separately; they have to do with the fact that there are several kinds of probability statements. Therefore, we will divide probabilistic inferences into:

- deductive probabilistic inferences

- inductive probabilistic inferences

- abductive probabilistic inferences

- cross-over probabilistic inferences

while the probability statements themselves will be divided into:

- purely mathematical

- frequency-objective

- singular-objective

- epistemic (subjective).

All statements in the calculus of probability are as purely mathematical as each statement in the multiplication table is. Therefore, they are not 
subject to empirical testing. However, all the other kinds of probability statements are empirically true or false. The most conspicuous objective probability statements are those describing relative frequencies, for example, the relative frequencies of heads and tails in coin tossing. We call them frequency-objective probability statements in contradistinction to singular-objective ones, which claim that there is an objective probability in a singular event or situation as such. Epistemic (or 'epistemological') probability statements are about how certain a person can be that a belief or an assertion is true, i.e., epistemic probability statements make claims about the relationship between knowledge subjects and the world. Therefore, they may also be called 'subjective' probability statements. Objective (or 'ontological') probability statements, on the other hand, make direct claims (true or not) about how the world in itself is in some respect.

The difference between objective and epistemic probability statements is most easily seen in relation to universal statements such as 'all men are mortal' and 'all metal pieces expand when heated'. Assertions such as 'probably, all men are mortal' and 'probably, all metal pieces expand when heated' are not meant to say that the relative frequency of mortals among men, and the relative frequency of expanding metal pieces among heated metal pieces, is high. They are meant to say that it is probably true (epistemology) that all men are mortal, and that it is probably true that all metal pieces expand when heated, respectively.

Note that it can be extremely hard, and often impossible, to transform with good reasons purely qualitative epistemic probability statements such as 'probably, all metal pieces expand when heated' into numerical epistemic probability statements such as 'with a probability of 0.8 it is true, all metal pieces expand when heated'.

An assertion such as 'probably, we will be visited by Joan on Friday' is out of context ambiguous. Depending on context, it can state either an epistemic probability or a frequency-objective probability. In one context it can mean that the speaker claims to have reasons (epistemology) to think that Joan, as it happens, will visit on the upcoming Friday, but in another it can mean that the speaker states that Joan usually visits on Fridays. In some cases, however, it is hard to distinguish between objective and epistemic probability statements. We will comment on this problem later 
when we present cross-over inferences (4.7.5). To begin with, we will explain in more detail the difference between frequency-objective and singular-objective probability statements.

\subsubsection{The die, the voter, and the medically ill-fated}

If a die that is made of a very hard material is thrown 60 million times, each of the sides comes up with a relative frequency of approximately $1 / 6$, i.e., 10 million times each. If 60 million such dice are thrown once simultaneously, each side will again come up with a relative frequency of approximately $1 / 6$. Think next of the following situation. There is a nation where 60 million citizens are allowed to vote, all of them do in fact vote, and none votes blank. There are six parties, and, according to a scientific investigation, each party will in the upcoming election get 10 million votes each. That is, the relative frequency of voters for each party is expected to be $1 / 6$. Let us now compare the statements

- the probability that this throw of this die will yield a side-2 is $1 / 6$

- the probability that this vote of this voter will be for the so-called party-2 is $1 / 6$ '.

Both these statements are, no doubt, formally singular-objective, i.e., from a purely grammatical point of view they talk about a singular throw and a singular vote, respectively. However, everyday language allows what is formally singular to be short-hand for what in fact is substantially nonsingular. For instance, 'Smith has 1.9 children' is formally singular but it makes no sense as a substantial singular-objective statement, and it means that the average number of children among couples in Smith's country is 1.9. Similarly, the singular-objective statement 'the probability that this throw of this die will yield a side- 2 is $1 / 6$ ' can be short-hand for the frequency-objective statement 'the relative frequency of side- 2 results is $1 / 6$ ', and the statement 'the probability that this vote of this voter will be for the party is $1 / 6^{\prime}$ can be short-hand for the frequency-objective statement 'the relative frequency of party-2 voters is $1 / 6$ '.

Now, let it be perfectly clear, our concept of 'singular-objective probability statements' is not meant to cover such cases of frequency statements in disguise. When we are talking about singular-objective 
probability statements, we are talking about statements that literally ascribe a probability to a singular event. Hereby, we are rejecting the positivist rejection of the concept of causality (Chapter 3.4); in relation to the interpretation of singular-objective probability statements, the overlap between science and philosophy becomes obvious. That there is a distinction between merely formal and substantive singular-objective statements can be made clear in several ways.

Assume, as before, that the relative frequency of party-2 voters is $1 / 6$ in the community as a whole, but that for people more than 50 years old it is $1 / 4$ and for males $1 / 5$. This means that for a male person over 50 (call him John), all the three following statements are in one sense true:

(a) 'the probability that John will vote for the party-2 is $1 / 6$ '

(b) 'the probability that John will vote for the party-2 is $1 / 4$ '

(c) 'the probability that John will vote for the party-2 is $1 / 5$ '.

But John cannot have all three probabilities as real singular-objective probabilities. This would be like weighing 75,70 , and $65 \mathrm{~kg}$ simultaneously. The three statements discussed have to be regarded as being merely short-hands for the corresponding three relative frequencies that are about (a) citizens in general, (b) citizens older than 50, and (c) male citizens, respectively. (And, according to positivism, this is all there is to be said.)

The distinction between singular-objective and frequency-objective statements concerned with voting behavior can also be highlighted in the following way. Obviously, a certain voter can hate all what party-2 represents. Therefore, there is no chance whatsoever that he will vote for it, i.e., the singular-objective statement 'the probability that this voter $\left(\mathrm{v}_{\mathrm{a}}\right)$ will vote for the party-2 is 0 ' is true. Another voter can be a fanatic party-2 member. He will vote for this party whatever happens, i.e., the singularobjective statement 'the probability that this voter $\left(\mathrm{v}_{\mathrm{b}}\right)$ will vote for the party-2 is 1 ' is true. All cases in-between probability 0 and 1 are also possible. In particular, there may be a voter that is searching for reasons to prefer one single party, but at the moment thinks that there are equally strong reasons for and against all the six parties. Since he $\left(\mathrm{v}_{3}\right)$ thinks that as a citizen he nonetheless has a duty to vote, it holds true of him: 'the 
probability that this voter $\left(\mathrm{v}_{3}\right)$ will vote for the party-2 is $1 / 6^{\prime}$. He is equally strongly torn in six different directions, i.e., he has six equally strong tendencies, but he can realize one and only one. He can grab a vote blindfolded, or let a random number generator make his choice.

With respect to each of the 60 million dice the situation is quite different. No die is pre-determined to come up with a side-2, and no die is pre-determined not to come up with a side-2. Why? Because all the dice are perfectly symmetrical. What can make a difference is the way the die is thrown, not the die itself. But since there are an infinite number of different such ways, it can be assumed that the ways the throws are made are as if they were chosen by a random number generator. If the dice are looked upon as human beings with inner reasons to act, then all the dice would be in the predicament of the voter that had equally good reason to vote for six different parties. Both such a voter and the dice tend in six different directions equally; the voter because his reasons for acting are symmetrical, the dice because its material structure is symmetrical.

What about singular persons in relation to medical probability statements? Well, unfortunately we have no definite answer, and we will only make some remarks hoping that future philosophy and science can make this area more clear. In our opinion, the only thing that at the moment can be said with certainty is that it is often hard to understand whether singular-objective medical probability statements are merely meant as short-hands for frequency-objective statements or as being literally meant. In the latter case, there ought to be some kind of similarity with dice, which inherit a definite singular-objective probability from their material structure. Of course, one should then think of a very asymmetrical die.

Let us assume that in a certain community, as far back as statistics are available, 1/6 of all the citizens between 45 and 65, the middle-aged ones, is infected by what is called 'disease-2'. One might then say about a particular such citizen John:

1. 'John runs a risk of $1 / 6$ to get disease-2'. 
However, if no more is said this statement has to be interpreted as being only formally singular-objective and short-hand for the mentioned frequency-objective statement:

1a. '1/6 of all the middle-aged persons, of which John is one, get disease-2’.

Despite the fact that statement $1 \mathrm{a}$ is true, John may run no risk at all to get the disease; he may be completely immune to it (compare with the voter that hates party-2). Conversely, he may be pre-determined to get the disease (compare with the fanatic party-2 voter). Both these states of affairs are quite consistent with the frequency-objective statement being true.

If the concept of tendency is allowed to be introduced, then statement 1 can be interpreted as a claim that each and every singular middle-aged person, John included, in fact has a tendency to contract or develop disease-2, but that there are unknown factors that prevent the realization of the tendency in five out of six cases. We should write:

1b. 'John has a tendency and real risk to get disease-2, but for some reason there is only a probability of $1 / 6$ that the tendency will be realized'.

Now the singular-objective statement 'John runs a risk of $1 / 6$ to get disease-2' ascribes a real property, a tendency, to John, but it allows no sure prediction of illness to be made.

Often in medical science, knowledge of one relative frequency or correlation triggers the search for an even more significant correlation. Let us introduce such a move in our probabilistic thought experiment. Here is a list of usual risk factors in epidemiological research: age, sex, race, ethnicity, family history, workplace chemicals, smoking habits, drinking habits, diet, weight, waist size, blood type, blood pressure, blood sugar, and cholesterol. Assume that the next investigation shows disease- 2 to correlate with, say, workplace chemicals in such a way that people exposed to the chemical called ' $\mathrm{Ch}$ ' for ten years are said to run a risk of 4/6 to get 
disease-2. What are we to say about this new probability statement? As far as we can see, the old interpretative problem simply reappears, even though now connected to a new factor with a higher probability. We arrive at the following three statements:

2. 'John runs a risk of $4 / 6$ to get disease-2'

2a. ' $4 / 6$ of all persons exposed to Ch, of which John is one, get disease-2'

2b. 'John has a tendency and real risk to get disease-2, but for some reason there is only a probability of $4 / 6$ that the tendency will be realized'.

One may search for still another new factor or combination of factors, but for every risk statement that contains a probability smaller than one, the problem of how to interpret the corresponding singular-objective probability statements will reappear. No relative frequency and correlation smaller than one can imply that a singular-objective risk statement is literally true.

We now will turn to the four different kinds of probabilistic inferences that we want the reader to become able to distinguish.

\subsubsection{Deductive probabilistic inferences}

If in a deductively valid schema like that to the left below, one exchanges the general premise for a corresponding premise about a relative frequency, then one obtains the deductively invalid schema to the right. Sometimes the latter is called a statistical syllogism (the term 'syllogism' is often used in philosophy as a synonym for 'valid inference'), but we will call it an inductive probabilistic inference. Instead of the usual inductive form, 'from some(-and-perhaps-all) to the next', it has the form 'from some(-but-not-all) to the next'. Here are the schemas: 
premise 1: all human beings are mortal $70 \%$ of all human beings are mortal

premise 2: Socrates is a human being Socrates is a human being hence:

conclusion: Socrates is mortal (INDUCTION)

Socrates is mortal

This does not mean that there are no probabilistic deductions. Mathematical inferences are deductive, and inferences made by means of the mathematical calculus of probability are proper deductions. Of course, as always in deduction, when it comes to evaluating the truth-value of the conclusion, one has to keep in mind what truth-value the premises have. Here is an example of a simple deductive probabilistic inference concerned with purely mathematical probability statements (but with one premise so far hidden):

$$
\begin{aligned}
& \mathrm{P}(\mathrm{A})=0.6 \\
& \mathrm{P}(\mathrm{B})=0.4 \\
& \mathrm{P}(\mathrm{A} \cdot \mathrm{B})=0.24
\end{aligned}
$$

It should be read: if the probability for an event of type A is 0.6 , and the probability for an event of type $B$ is 0.4 , then the probability for both events to occur is 0.24 . If there is a chance of 0.6 to win in one lottery and a chance of 0.4 to win in another lottery, then there is a chance of 0.24 to win in both lotteries. However, as the inference explicitly stands, it is not deductively valid. It is so valid only on the condition that the probability stated for $\mathrm{A}$ is independent of the probability stated for $\mathrm{B}$, and vice versa. This requirement is part of the mathematical probability calculus, and it is mathematically expressed as ' $\mathrm{P}(\mathrm{A} \mid \mathrm{B})=\mathrm{P}(\mathrm{A})$ '. It could just as well have been written ' $P(B \mid A)=P(B)$ '; these two equalities imply each other. The formula ' $\mathrm{P}(\mathrm{A} \mid \mathrm{B})=\mathrm{P}(\mathrm{A})$ ' should be read:

- the (relative) probability of an event $\mathrm{A}$ given an event $\mathrm{B}$ equals the (absolute) probability of an event A. 
It states that the probability of an event of type A remains the same whether or not an event of type B has occurred or obtains. The following probabilistic inference is without qualifications deductively valid:

$$
\begin{aligned}
& P(A)=0.6 \\
& P(B)=0.4 \\
& P(A \mid B)=P(A) \\
\text { hence: }--- & P(A \cdot B)=0.24
\end{aligned}
$$

How shall this inference be looked upon if ' $\mathrm{P}(\mathrm{A})=0.6$ ', ' $\mathrm{P}(\mathrm{B})=0.4$ ', and ' $\mathrm{P}(\mathrm{A} \mid \mathrm{B})=\mathrm{P}(\mathrm{A})$ ' are not purely mathematical but objective probability statements? Answer: the inference is still valid. If the premises states truths about some relative frequencies, then the conclusion states a truth about a relative frequency too. However, since the premises are empirical statements they might be false and, therefore, one may feel uncertain about the truth of the conclusion. Deductions are, as we have said, truthpreserving inferences, but if one is uncertain about the truths of the premises, such inferences may be called 'uncertainty-preserving'. A deductively valid inference cannot reduce the epistemic uncertainty of the premises.

What then if ' $\mathrm{P}(\mathrm{A})=0.6$ ', ' $\mathrm{P}(\mathrm{B})=0.4$ ', and ' $\mathrm{P}(\mathrm{A} \mid \mathrm{B})=\mathrm{P}(\mathrm{A})$ ' are subjective (epistemic) probability statements? In one sense, what has just been said about objective probabilities applies to subjective probabilities too. However, two things have to be noted. First, the probability calculus is about numerical probabilities, but, normally, it is difficult, not to say impossible, to ascribe numerical values to epistemic statements. In many situations, it is easy to put forward vague but true subjective probability statements such as 'probably, it will soon start to rain', but senseless to state ' $\mathrm{P}$ (it will soon start to rain $)=0.6$ '; or some other definite number.

Second, deductive inferences can only relate sentences that express something that can be regarded as true or false. This means that if an epistemic assertion such as 'probably, all men are mortal' is put into a deductive inference, then it has to be read as saying 'it is true: probably, all 
men are mortal'. This is not odd. To assert simply 'all men are mortal' is also to assert, but implicitly, 'it is true: all men are mortal'. Usually, this implicit level is made explicit only when the truth of an assertion is questioned and people are forced to reflect on and talk about their assertions.

Some illustrating words now about deductive inferences in relation to the classical example of relative frequencies: playing dice. What is the probability of getting two ' 5 ' when throwing a die twice? As premises, we assume that the probability to get ' 5 ' on the first throw, $A_{1}$, is one sixth, and the same holds true for the second throw, $A_{2}$. We have:

- $\mathrm{P}\left(\mathrm{A}_{1}\right)=1 / 6$, and $\mathrm{P}\left(\mathrm{A}_{2}\right)=1 / 6$.

If the probability calculus is applied, we can deductively infer that the probability of getting two ' 5 ' in succession is $1 / 36$ :

- $\mathrm{P}\left(\mathrm{A}_{1} \cdot \mathrm{A}_{2}\right)=\mathrm{P}\left(\mathrm{A}_{1}\right) \cdot \mathrm{P}\left(\mathrm{A}_{2}\right)=1 / 36$.

Since the general (objective) probability statement ' $\mathrm{P}(\mathrm{A})=1 / 6$ ' is an empirical statement about the die that one starts to use, one can never know for sure that it is true. Furthermore, even if the die is absolutely symmetric and has the probability one sixth for each side when one starts to throw, it is possible that the first throw changes the symmetry and the probabilities of the die and, thereby, makes ' $\mathrm{P}\left(\mathrm{A}_{2}\right)=1 / 6$ ' false. Another way of expressing this last possibility is to say that the probability for the throw $A_{2}$ may depend on $\mathrm{A}_{1}$. If one of the premises ' $\mathrm{P}\left(\mathrm{A}_{1}\right)=1 / 6$ ' and ' $\mathrm{P}\left(\mathrm{A}_{2}\right)=1 / 6$ ' is false, then the conclusion ' $\mathrm{P}\left(\mathrm{A}_{1} \cdot \mathrm{A}_{2}\right)=1 / 36$ ' need not be true, but the probabilistic inference in question is nonetheless deductively valid.

Singular-objective probability statements such as 'the probability of getting a five (A) in the next throw of this die is $1 / 6$ ' (' $P(A)=1 / 6$ ') can just like many other empirical hypotheses be argued for by means of hypothetico-deductive arguments. The reason is that from such a singularobjective statement one can (if the number $\mathrm{n}$ is large) deduce a relative frequency: 
hypothesis: $\quad \mathrm{P}(\mathrm{A})=1 / 6$

initial condition 1: die $\mathrm{D}$ is thrown $n$ times

initial condition 2: during the test, $\mathrm{D}$ does not change any relevant properties

hence:

test implication: $\quad$ approximately, $n \cdot(1 / 6)$ of the throws will yield A

As we have explained earlier, such a deductive schema has to be complemented with an inductive inference that goes in the opposite direction, i.e., from the test implication and the initial conditions to the hypothesis; because from a relative frequency (the test implication) one cannot deduce a singular-objective probability (the hypothesis). Let us now proceed to induction in probabilistic contexts.

\subsubsection{Inductive probabilistic inferences}

We have distinguished between two kinds of induction: 'from some to the next' and 'from some to all'. Both have in their own way probabilistic versions. In relation to the first kind, one version has the form 'from somebut-not-all to the next' or 'from $x \%$ to the next', as below:

deduction

premise 1: all persons having disease $\mathrm{D} \quad \mathrm{x} \%$ of the persons having have symptoms $\mathrm{S}$

premise 2: patient $a$ has disease $\mathrm{D}$ hence:

conclusion: patient $a$ has symptom S

\section{probabilistic induction} disease $\mathrm{D}$ have symptoms $\mathrm{S}$ patient $a$ has disease D

patient $a$ has symptoms $\mathrm{S}$

If $\mathrm{x}$ is a small number, the inductive conclusion would rather be 'patient $a$ does not have symptoms S'.

The next two schemas represent other versions of inductive probabilistic inferences. In the first, the conclusion is expressed by a singular-objective probability statement; in the second, it is expressed by a frequencyobjective statement. It has to be added that 'some $(=n)$ ' now has to mean 'many'; the number $n$ has to be large. Since the inferences are inductive there is in neither case any truth-preserving, i.e., the frequency-objective 
probability statement of premise 1 can in both cases only give inductive support to the conclusion:

premise 1: $\quad 1 / 6$ (approximately) of the $n$ throws with the die $\mathrm{D}$ have yielded A

premise 2: during the test, the die $\mathrm{D}$ did not change any relevant properties

hence: (INDUCTION)

conclusion: in the next throw of $\mathrm{D}: \mathrm{P}(\mathrm{A})=1 / 6$

An inductive generalization of dice throwing has to go in two directions. It has to generalize to all throws of the die spoken of and it has to generalize to all dice of the same kind. We then have this schema:

premise 1: $1 / 6$ (approximately) of the $n$ throws with the dice have yielded A

premise 2: during the test, the dices did not change any relevant properties

hence: (INDUCTION)

conclusion: in any large number of throws, approximately 1/6 will yield A

In statistics, one talks about inferences from a random sample to a whole population. In such terminology, the first premise in the last schema describes a sample and the conclusion describes the corresponding population. This population is in principle infinitely large, as they are in all probabilistic natural laws, but populations can just as well be finite. In either case, however, statistical data-material can provide no more than inductive support to the relative frequencies in the populations. The fact that the statistical move from sample to population is not deductive and truth-preserving is sometimes overlooked. One reason is that it is quite possible to use the hypothetico-deductive method in actual research without keeping the deductive and the inductive inferences explicitly separated in the manner we are doing in this chapter. What in fact is a mix of induction and deduction and, therefore, contains the uncertainty of 
induction, may then falsely appear as having the certainty of a pure deduction.

Another reason that the statistical move from sample to population is falsely regarded as deductive might be that some people who use probability statements do not distinguish between substantial singularobjective probability statements and merely formal such statements. We explained this distinction in Section 4.7.2, but let us repeat the point with a new example:

premise 1: $2 \%$ of all delivering women at hospital $H$ have been infected with childbed fever

premise 2: the woman $\mathrm{W}$ is going to deliver at $\mathrm{H}$

hence:

conclusion: the probability (risk) that $\mathrm{W}$ might be infected by childbed fever is $2 \%$

The conclusion allows two different interpretations, one which turns the preceding inference into a deduction, and one which keeps it inductive. On the one hand, the conclusion can be interpreted as another way of stating only and exactly what is already said in the premises. While it sounds as if there is talk only about the next patient (singular-objective statement), in fact, there is talk only about a group of earlier patients (frequencyobjective statement). Such an interpretation of the conclusion makes of course the inference in question deductively valid, but also uninformative.

On the next interpretation, whereas the first premise (as before) says something about the past, the conclusion says something about the future. The conclusion is a singular prediction, and it may turn out to be false even if the premises are true. That is, $\mathrm{W}$ may in fact be immune to childbed fever and have no risk at all to become infected.

\subsubsection{Abductive probabilistic inferences}

We have distinguished between two kinds of abduction: to a known and to an unknown kind, respectively. Both have probabilistic versions. If we replace the general premise of an ordinary clinical abduction to a known kind by a corresponding premise about a relative frequency, we arrive at the following probabilistic abduction: 
Prototypical abduction

premise 1: all persons having disease $\mathrm{D}$ have symptoms $\mathrm{S}$

premise 2: patient $a$ has symptoms $\mathrm{S}$ hence:

conclusion: patient $a$ has disease $\mathrm{D}$
Probabilistic abduction

$\mathrm{x} \%$ of the persons having disease D have symptoms $\mathrm{S}$ patient $a$ has symptoms $\mathrm{S}$

patient $a$ has disease $\mathrm{D}$

Of course, a probabilistic abduction is more unreliable than the corresponding prototypical one, and the lower the relative frequency is, the more unreliable is the inference. To take a concrete example: should a general practitioner ever send a patient suffering from headache to a brain MRI (magnetic resonance imaging)? The overwhelming majority of patients suffering from headaches have no brain tumor. But the single patient in front of the doctor might be the rare case. Probabilistic abduction has to rely very much on the content at hand. The abductive inference form does not in itself transmit much epistemic credibility from the premises to the conclusion.

Abduction to an unknown kind has also its place in statistics related to medicine and some other sciences. What is unknown is then the statistical model that is fitting for some kind of research. After a statistical model has been chosen, one knows fairly well both how to find the sample and how to move from the sample to the population, but what kind of statistical model to choose is at the start an open question. Often, the situation is such that one can choose an already existing model, but sometimes the model itself has to be created. In the latter case there is true abduction to an unknown kind - to an unknown kind of statistical model.

\subsubsection{Cross-over probabilistic inferences}

From the preceding three sections it should be clear that the traditional formal schemas for deductive, inductive, and abductive inferences allow the introduction of probability statements. In these sections it was tacitly assumed that the premises-statements and the conclusion-statement are of the same general character: (a) purely mathematical, (b) objective, or (c) epistemic. Now we will present some inferences where the premises are 
frequency-objective (ontological) statements and the conclusion is a subjective (epistemological) probability statement. We call them crossover probabilistic inferences, and we present them because if they are not clearly seen, then some of our earlier remarks may look odd. Here are the first two varieties:

\section{cross-over probabilistic inference (i)}

premise 1: the relative frequency of persons with disease $\mathrm{D}$ that get cured by recipe $\mathrm{R}$ is high (say, 0.95)

premise 2: $\quad$ patient $a$ has disease $\mathrm{D}$ and gets $\mathrm{R}$

hence:

conclusion: the epistemic probability that patient $a$ will be cured by $\mathrm{R}$ is 1

cross-over probabilistic inference (ii)

premise 1: the relative frequency of persons with disease $\mathrm{D}$ that get cured by recipe $\mathrm{R}$ is small (say, 0.05 )

premise 2: $\quad$ patient $a$ has disease $\mathrm{D}$ and gets $\mathrm{R}$

hence:

conclusion: the epistemic probability that patient $a$ will be cured by $\mathrm{R}$ is 0

Both these inferences may at first look spurious, turning ' 0.95 ' into ' 1 ' and '0.05' into '0', respectively, but they aren't. For two reasons. First, often when we act it is impossible to have a distanced attitude thinking that the outcome is only probable and not ensured. Therefore, transitions from various frequency-objective statements to the epistemic and subjective probabilities one and zero are often needed. Second, the relative frequencies in question do not rule out the cases that the patient $a$ may surely be cured and not cured, respectively.

In the third variety, a cross-over inference assigns the numerical value of the relative frequency to the epistemic probability in the conclusion. This is of course also possible. In this case, it is interesting to make a comparison with the inductive transition from a frequency-objective statement to a 
realistically interpreted singular-objective statement. Here are the two schemas:

\section{cross-over probabilistic inference (iii)}

premise 1: $\quad$ the relative frequency of persons with disease $\mathrm{D}$ that get cured by recipe $\mathrm{R}$ is $0 . \mathrm{x}$

premise 2: $\quad$ patient $a$ has disease $\mathrm{D}$ and gets $\mathrm{R}$

hence:

conclusion: the epistemic probability that $a$ will be cured by $\mathrm{R}$ is $0 . \mathrm{x}$

\section{inductive probabilistic inference}

premise 1: the relative frequency of persons with disease $\mathrm{D}$ that get cured by recipe $\mathrm{R}$ is $0 . \mathrm{x}$

premise 2: $\quad$ patient $a$ has disease $\mathrm{D}$ and gets $\mathrm{R}$

hence:

conclusion: the singular-objective probability that $a$ will be cured by $\mathrm{R}$ is $0 . \mathrm{X}$

Some of the confusions that surround probability talk has, we think, its root in the fact that sometimes two different kinds of probability statements with the same numerical probability - such as the statements 'the epistemic probability that $a$ will be cured by $\mathrm{R}$ is $0 . \mathrm{x}$ ' and 'the singular-objective probability that $a$ will be cured by $\mathrm{R}$ is $0 . \mathrm{x}^{\prime}$ - can be inferred from exactly the same premises. That is, the brief singular statement 'the probability that $a$ will be cured by $\mathrm{R}$ is $0 . \mathrm{x}$ ' may be regarded as fusing two theoretically distinct meanings. It may have practical advantages, but it may also have the negative consequence that the problem of the interpretation of singularobjective probability statements (highlighted in Sections 4.7.1 and 4.7.2) becomes hidden. We guess that there is much more to say and make clear here, but we will not try to do it.

\subsection{Harvey's scientific argumentation}

We will now, by means of an example from the history of medical science, highlight how different types of arguments can be woven together when a 
radically new theory is argued for. Our example is taken from William Harvey's once revolutionary book about the movement of the heart and blood circulation in animals', Exercitatio Anatomica de Motu Cordis et Sanguinis in Animalibus (1628), usually abbreviated as De Motu Cordis. This work has rightly been praised as an excellent example of how medical research should be conducted. But, of course, all medical research cannot have such a pioneering character.

As we have earlier mentioned (Chapter 2.3), Harvey's views became essential parts of the criticism and eventual rejection of Galen's theories. According to Galen, food is convened into blood in the liver, from which the blood goes to the right part of the heart, where it is heated, and then it moves through the other blood vessels in a centrifugal direction out into the organs, extremities and tissues where the blood is consumed. Moreover, the left part of the heart is, according to Galen, assumed to contain the so called vital spirit, which is supposed to be distributed from this side of the heart to the rest of the body.
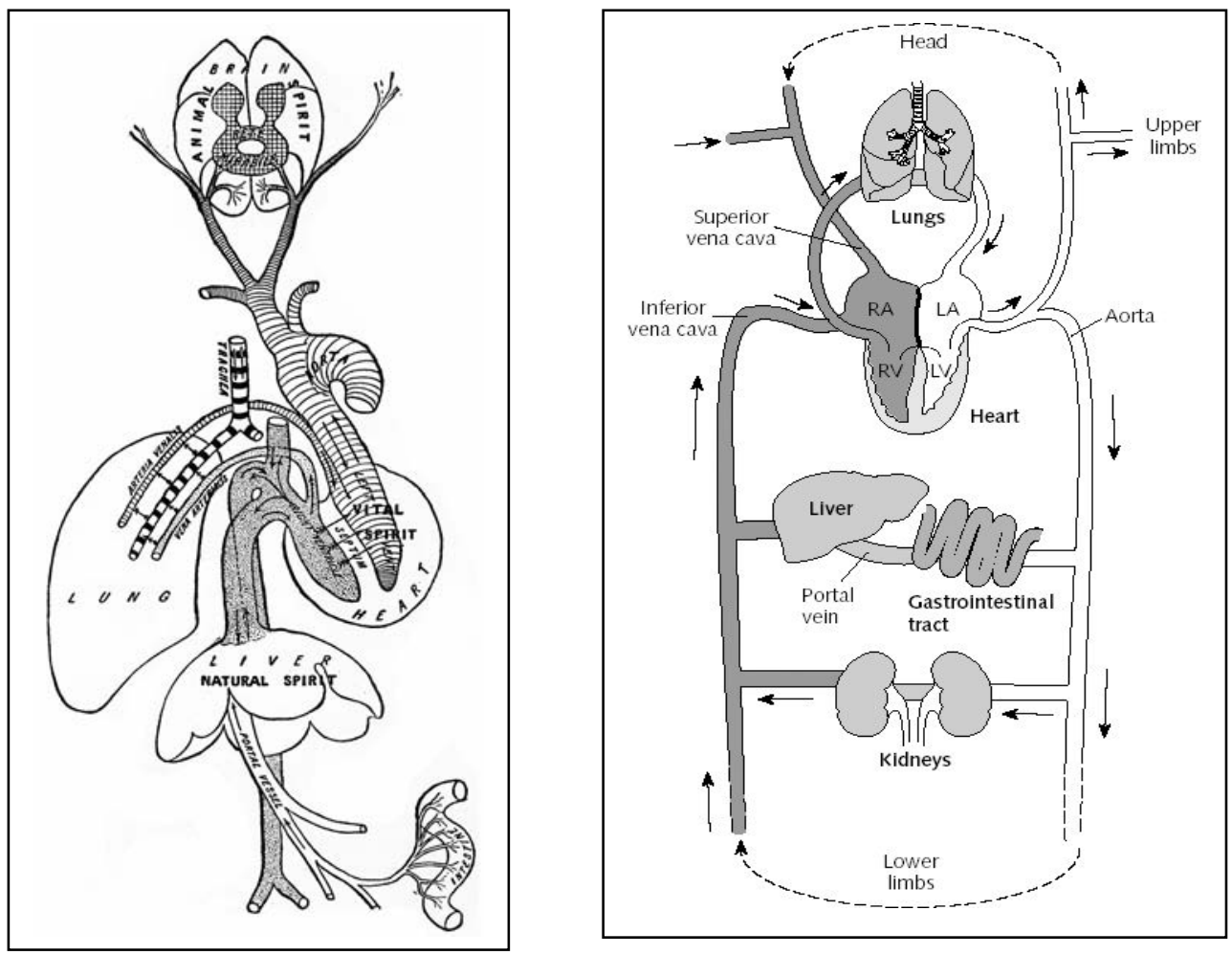

Figure 2: Galen's and Harvey's views of the body. 
According to Harvey, the blood moves in two circles in relation to the heart, a minor and a major circulation. In the minor circulation, the blood moves from the right side heart-chamber or ventricle via the pulmonary artery to the lungs, passes through the lungs, and goes via the pulmonary veins back to the left side atrium or auricle of the heart. From here, the blood is pumped into the left side heart-chamber, and from this ventricle the major circulation starts. The blood is pumped into the large body arterial vessel (the aorta) and further into the different organs and tissues. When the bloodstream has passed the organs and tissues it returns to the right side auricle of the heart via the veins. From this auricle, the blood is pumped into the right side chamber, and back to the minor circulation, i.e., back to where it started from (see Figure 2).

According to modern terminology, arteries are vessels that lead the bloodstream away from the heart, and veins are vessels that lead the bloodstream towards the heart. All arteries except the pulmonary artery are carrying blood saturated with oxygen, and all veins except the pulmonary vein are carrying deoxygenated blood. It is important to underline the fact that the function of the lungs and oxygenation was not yet discovered. Malpighi discovered the capillary circulation in the lungs in 1661, which before this discovery, provided an anomaly in Harvey's theory. But it was not until the chemical theory of oxygen was discovered (around 1775) that we got the modern explanation of the function of the lungs. (Compare Harvey's and Galen's views as represented in Figure 2.)

The partly new situation that Harvey could benefit from can be summed up in the following way:

1. It had become accepted that physicians could question the old authorized knowledge, and that there were reasons to make one's own observations and experiments.

2. It had become legitimate for physicians to perform dissections of human corpses.

3. The idea that blood may circulate had already been suggested by Realdo Colombo (1516-1553) and Andrea Cesalpino (1519-1603), but it had not become accepted.

4. The existence of the minor circulation of blood had already been described by Colombo and Michael Servetus (1511-1553). 
5. There were some speculations concerning the possibility of capillary passages in the tissues.

6. During dissections of corpses, blood had been observed both in the left heart chamber and in the large arterial vessels.

7. Small pores in the walls between the right and the left chambers of the heart, as assumed by Galen, could not be observed.

Harvey was an Englishman, but he had studied in Padua under the famous anatomist Hieronymus Fabricius, who discovered the valves in the veins. For a brief time, he was contemporary Francis Bacon's (see Chapter 3.4) physician. In all probability, Harvey was influenced by Bacon's philosophy. Especially, it has been claimed, he was inspired by the Novum Organum (1620) in which Bacon argued that one should make "induction upon data carefully collected and considered."

Harvey made meticulous and repeated observations in order to obtain inductive support for his theories. However, before we present Harvey's ways of argumentation, we would like to give a summery of Galen's views. In order to understand Harvey, one has to know what he was arguing against (see also Chapters 2.3 and 2.4).

According to Galen:

1. The heart is neither a pump nor a muscle, it is a passive reservoir; due to the movements of the chest it has a certain suction-capacity that helps the blood to go from the liver to the heart.

2. The heart is also a thermal unit whose function is to keep the blood thin and liquid.

3. The blood vessels contain, apart from the sanguine fluid, even black bile, yellow bile, and phlegm. Together these make up the four basic bodily fluids (not to be conflated with the three kinds of spirits or pneuma mentioned in point 6 below).

4. The right heart-chamber keeps the blood in a lapping movement whereby the four fluids are mixed.

5. There is blood mainly in the veins - the vessel system connected to the right part of the heart - and the bloodstream moves towards the periphery slowly according to the pace at which it is produced in the liver and consumed in organs, extremities and tissues. It departs from 
the liver and goes to the right part of the heart, where it is heated, and then further from the heart to the periphery of the body.

6. There are three kinds of spirits: a) spiritus animalis, which is produced in the brain, is distributed along the assumed hollow nerves, and whose functions are related to perception and movement; b) spiritus vitalis, which is produced in the left part of the heart, is distributed by the arteries, and whose function is to 'vitalize' the body and to keep the body warm; c) spiritus naturalis, which is produced in the liver, but goes to and passes through the right part of the heart, and whose function is to supply the organs and tissues with nutrition.

7. The left side of the heart chamber and the arterial vessels containing spiritus vitalis are together considered to be merely a pneumatic system connected with the lungs and air-pipe, which was also categorized as an artery.

8. There are pores in the wall (septum) between the two heart chambers. By means of these pores blood can percolate from the right side to the left side, where it is mixed with the air and then sublimated into spiritus vitalis.

9. There are two kinds of vessels: arteries and veins. Arteries depart from the left side of the heart and contain spiritus vitalis and these vessels are pulsating by means of a kind of (peristaltic) movement in the artery walls. The vessel system made up of veins contains blood, for instance, 'the artery-like lung vein', which we currently define as an artery (a. pulminalis). What we today refer to as the lung veins was according to the Galenic theory referred to as a vein-like artery. (In some languages, arteries and veins have names that can be translated into English as 'pulsating vessel' and 'blood vessel'; in German, "Pulsader” and “Blutader”, respectively.)

Now, against this background, how did Harvey proceed and argue? Those who have observed a living heart know how hard it can be to have a clear picture of what definite pattern that the rather fast movements of the heart constitute. It is by no means immediately obvious that the heart functions like a pump. Harvey, however, developed an experimental technique that made it possible to examine dying animal hearts. Since these perform only 
a few beats per minute, it became easier to see that the heart might function as a pump.

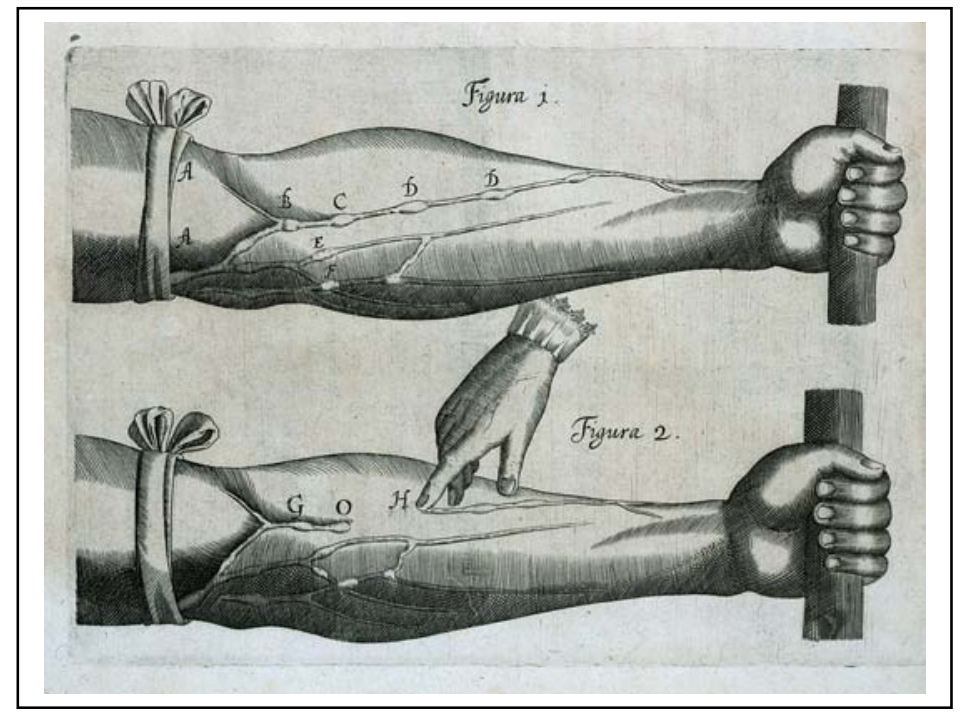

Figure 3: Experiment made by Harvey.

Harvey also figured out the following simple but ingenious experiment. He bound a string around an arm and observed what happened. The experiment is illustrated in one of the few figures in De Motu Cordis (Figure 3).

Considering the theories of Galen, his own hypothesis, and his own observations, Harvey might have reasoned somewhat as follows:

I. What to expect according to Galen? According to Galen's theory, the direction of the bloodstream in the arms is only outwards, and we might thus expect an accumulation of blood proximally to the string. Distally to the string, the blood vessels should fade away and finally collapse.

II. What do we observe? The blood vessels proximally to the string fade away, while the blood vessels distally to the string become swollen. When we the string is taken away, the proximal blood vessels appear again whereas the swelling disappears. 
III. What conclusions can be drawn? As we have explained in Section 4.6, definite conclusions need auxiliary hypothesis. Now, some hundreds years later, it is easy to say that there were no good auxiliary hypotheses to be found, but at the moment of this experiment things could not be regarded as definitely settled. Nonetheless one might say that at first sight the outcome of Harvey's experiment falsifies Galen's theory. Obviously, Harvey demonstrated a serious anomaly within the Galenic paradigm. The same observation, conversely, supported Harvey's own view that the blood in the veins is streaming towards the heart; quite contrary to the Galenic teachings.

In another experiment Harvey lanced the main pulse artery - the aortic vessel - in a living animal. Let us look at the argumentation:

I. What do we expect according to Galen? We might expect that something air-like, spiritus vitalis, would stream out; or, at least, a mixture of something air-like and blood.

II. What do we observe? Blood, and only blood, is splashed out.

III. What conclusions can be drawn? Again, hypothetico-deductive argumentation tells against the Galenic theory, i.e., that there is again a serious anomaly. Harvey's experiment displayed a considerable discrepancy between what the Galenic theory (in its actual form) predicted and what was observed. It also generated the hypothesis that the left part of the heart and the arterial system contains blood.

Harvey made more experiments with the same kind of conclusions. The Galenic theory became confronted not only with one or two, but with several unexpected empirical phenomena. In this phase, however, Harvey had only begun his journey towards his theory. Many things remained to be explained before he was able to provide a coherent and reasonable alternative. In this work, Harvey also uses some thought experiments and reductio ad absurdum arguments.

If, Harvey asked himself, the function of the lung vein (today we refer to this as the pulmonary artery as the bloodstream depart from the heart) is to supply the lungs with spiritus naturalis (nutrition), why are they so big 
(thick) compared to other veins with a similar function, e.g., those in the legs? Ought not vessels that have the same function have somewhat similar dimensions? Furthermore, if nonetheless there can be a difference, shouldn't it go in the other direction? Since the legs are larger than the lungs, shouldn't the vessels supplying the legs with nutrition be bigger than those supplying the lungs with nutrition? Merely by thinking about Galen's theory, Harvey managed to discover an absurdity.

Harvey used an abductive and (at the same time) analogical inference when he argued that the heart is a muscle. If we touch a muscle, e.g., the biceps, we will find it soft and relaxed when it is not used, but hard and tensed when it is used. Correspondingly, when we touch a small and hard heart it feels like a tensed biceps, and when it is enlarged and dilated it feels like a relaxed biceps. If we call the phenomenon 'feels like biceps', we can write:

$\begin{array}{ll}\text { premise 1: } & \text { all muscles feel like biceps } \\ \text { premise 2: } & \text { the heart feels like biceps } \\ \text { hence: } & \text {------------------ (ABDUCTION and ANALOGY) } \\ \text { conclusion: } & \text { the heart is a muscle }\end{array}$

Simplicity arguments come in when Harvey argues against the view that there are invisibles pores in the wall between the heart chambers. The transport of blood from the right side to the left side of the heart is explained more simply by the assumption that the bloodstream pass the lung veins and the porous lungs.

When Harvey argued for the existence of the minor circulation, he used analogy reasoning. According to Harvey's assumption, the blood passes the lungs. How is this possible? Harvey gave the following answers:

there might be an $X$ that is to (can pass through) the porous lungs what blood is to the compact liver hence: (ANALOGY)

blood is to (can pass through) the porous lungs what blood is to the compact liver 
there might be an $X$ that is to (can pass through) the porous lungs what urine is to the compact kidneys

hence: (ANALOGY)

blood is to (passes through) the porous lungs what urine is to the compact kidneys

In his description of the relationship between the functions of the auricles and the ventricles of the heart, Harvey used a simple analogy with a pistol. He maintained that the auricles and ventricles together was "as a piece of machinery, in which, though one wheel gives motion to another, yet all the wheels seem to move simultaneously”. If things can work in this manner in a weapon, things may work in the same way in the body.

In a special argumentation, Harvey made an analogy between, on the one hand, the heart and the circulation of the blood and, on the other hand, the sun and the circulation of water in nature. When heated by the sun, the humidity of the fields and the water of the oceans rise into the air. When in the air, the water is condensed into rain clouds that eventually produce raindrops that fall down on the earth; thereby creating humidity in the fields and water in the oceans. This analogy made a strong impact, since many people at this time believed in a general correspondence between micro-cosmos and macro-cosmos.

Harvey also uses ad hominem arguments. Indeed, when Harvey highlights an argument, or some precondition for an argument, he often refers to authorities and uses phrases such as 'the prominent anatomist Colombo'. So he did, for instance, when he argued that it is possible for the bloodstream to pass the compact liver tissue, which was a premise in one of the analogy arguments mentioned above.

One kind of ad hominem argument was the ad divinum argument. For example, one of Harvey's arguments in support of the hypothesis that blood was circulating was that circular movements are more perfect, beautiful, divine and therefore desirable than straight ones. According to Harvey, this is a manifestation of God's great creativity. In these times, a reference to God was understood as a special kind of ad hominem argument, or, more correctly, ad divinum argument.

When qualitative reasoning is converted into quantitative, new and interesting conclusions often appear. According to Galen, the velocity of 
the bloodstream was mainly determined by the speed in which the liver produced the blood; and the volume of blood streaming from the heart to the other organs and tissues was assumed to be rather small. Harvey, as we have seen, assumed that the heart is a muscle, which - due to contractions - pumps the blood into the artery system; and that due to the shape of the heart valves, the blood cannot return to the heart chambers. Having looked at hearts, Harvey assumed that the left chamber contains approximately half an ounce of blood, and then he multiplied this volume with the number of heartbeats per minute. The interesting conclusion was that during half an hour the heart pumps out a volume of blood that is much larger than that estimated for the body as a whole. No one thought that such a quantity of blood could be produced during that interval in the liver, and consumed in the organs and tissues. That is, thanks to Harvey's quantitative thinking the Galenic theory was faced with still another difficult anomaly.

The fact that the Galen's theory of the blood and the heart was shown to contain both many empirical anomalies and some theoretical inconsistencies, and eventually was rejected in favor of Harvey's, does not mean that Harvey would have been better off starting from scratch. Mostly, it is better to start from a false theory than from no theory at all. It should also be remembered that Harvey did not break with Galen in all aspects. For instance, he never questioned the concept of 'spiritus', which is a bit astonishing since he assumed that all arteries, veins, and both sides of the heart contain one and the same substance, blood. Nor did he question the view that blood is composed of the four old bodily fluids. Furthermore, like Galen, Harvey regarded the heart as also being a kind of heater - a sun in the microcosmos constituted by the human body. He thought that the percolation of blood through the lung also had the function to temper the blood and make sure that it should not start to boil.

Now leaving his theory of blood circulation behind, it is also interesting to note that Harvey, despite his careful empirical observations, never questioned the old but false view that nerve fibers are hollow. On the other hand, he did question the new and true view that there is a lymph system. This system was discovered by Thomas Bartholin (1616-1680) in 1653, but Harvey refused to accept this finding. The existence of lymph vessels had been demonstrated by vivisection on dogs; they had been described as 'white veins' containing a milky fluid. In order to provide an explanation 
of this to him seemingly odd phenomenon, Harvey maintained that the vessels in question were nothing but nerve fibers. The fact that Harvey primarily had studied fishes and birds - animals with no lymph systems might also have influenced his interpretation of the 'white veins'. Empirical examinations were important in Harvey's scientific work, but his denial of the existence of a third system, the lymph system, illustrates the view that observations are theory-laden.

Harvey did not bother about any distinction between a 'context of discovery' and a 'context of justification'. At the same time as he provided arguments against the Galenic theory, he also generated his own hypotheses and produced arguments in favor of these. He did not first produce a well formulated and in detail specified theory, which he later started to test in accordance with the pattern for hypothetico-deductive arguments.

Hopefully, our presentation of Harvey has given credence to our view that scientific argumentation is often composed of different but intertwined kinds of argument. Harvey used interchangeably:

1) Arguments from perceptions (i.e., direct ocular and palpating observations as well as observations based on experiments)

2) Inductive inferences (what is true of some human bodies are true of all)

3) Hypothetico-deductive arguments

4) Abductive inferences

5) Thought experiments and reductio ad absurdum arguments

6) Arguments from simplicity, beauty, and analogy

7) Ad hominem arguments

Arguments can, as we said at the beginning of this chapter, be connected to each other both as in a chain and as in a wire. Harvey, we would like to say, mostly wired his deductions, inductions, abductions, and other kinds of arguments. But even such a wiring cannot change the fact that empirical theories and hypotheses are epistemologically underdetermined. Fallibilism reigns, and not even a huge dose of tacit knowledge, which will be discussed in Chapter 5, can alter this fact. Tacit knowledge is fallible knowledge too. 


\subsection{Has science proved that human bodies do not exist?}

We started this chapter by presenting formal-logical deductive inferences. In passing, we said that there is seldom need in actual science to make these explicit. But 'seldom' is not 'never'. Science overlaps with philosophy, and we will end this chapter by returning to logical contradictions. Medical science takes the existence of material bodies for granted, but in philosophy this assumption is questioned both by traditional idealists (claim: there are only souls and mental phenomena) and modern linguistic idealists (claim: we can only know conceptual constructs). Sometimes, even science itself is referred to as having shown that there are no material bodies. But then, mostly, the critics contradict themselves as in the quotation below, which comes from the advertisement of a book entitled Matter. The Other Name For Illusion (author: Harun Yahya). The advertisement says:

All events and objects that we encounter in real life - buildings, people, cities, cars, places - in fact, everything we see, hold, touch, smell, taste and hear-come into existence as visions and feelings in our brains.

We are taught to think that these images and feelings are caused by a solid world outside of our brains, where material things exist. However, in reality we never see real existing materials and we never touch real materials. In other words, every material entity which we believe exists in our lives, is, in fact, only a vision which is created in our brains.

This is not a philosophical speculation. It is an empirical fact that has been proven by modern science. Today, any scientist who is a specialist in medicine, biology, neurology or any other field related to brain research would say, when asked how and where we see the world, that we see the whole world in the vision center located in our brains.

These paragraphs imply, to put it bluntly, (a) that everything we encounter in perception exists in an existing material thing called brain, and (b) that 
there exist no material brains. But it is a logical contradiction to claim both that there are material brains and that there are not. Hopefully, most medical scientists and clinicians will continue to believe that our brains are material things and that we know at least something about how they are structured and function.

\section{Reference list}

Aristotle. Metaphysics (book IV). (Many editions.)

Bunge M. The Myth of Simplicity. Prentice Hall. Englewood Cliffs, N.J. 1963.

Chalmers AF. What is This Thing Called Science? Hackett Publishing. Indianapolis 1999.

Coady CAJ. Testimony: A Philosophical Study. Oxford University Press. Oxford 1992.

Davidson A. Styles of Reasoning. In Galison P, Stump G (eds.). The Disunity of Science. Stanford University Press. Palo Alto 1996.

Hanson NR. Patterns of Discovery. Cambridge 1958.

Harrowitz N. The Body of the Detective Model - Charles S. Peirce and Edgar Allan Poe. In Eco U, Seboek TA (eds). 'The Sign of Three. Dupin, Homes, Peirce.' Indiana University Press. Bloomington 1983.

Harvey W. Anatomical Studies on the Motion of the Heart and Blood (translated by Leake C). Springfield 1978.

Hempel C. Aspects of Scientific Explanation. The Free Press. New York 1965.

Hempel C. Provisoes: A Problem Concerning the Inferential Function of Scientific Theories. Erkenntnis 1988; 28: 147-64.

Jansen L. The Ontology of Tendencies and Medical Information Sciences. In Johansson I, Klein, B, Roth-Berghofer T (eds.). WSPI 2006: Contributions to the Third International Workshop on Philosophy and Informatics. Saarbrücken 2006.

Johansson I. Ceteris paribus Clauses, Closure Clauses and Falsifiability. Zeitschrift für allgemeine Wissenschaftstheorie 1980; IX: 16-22.

Kalman H. The Structure of Knowing. Existential Trust as an Epistemological Category. Swedish Science Press. Uppsala 1999.

Lexchin J, Bero LA, Djulbegovic B, Clark O. Pharmaceutical industry sponsorship and research outcome and quality: systematic review. British Medical Journal 2003; 326: 1167-70.

Mowry B. From Galen's Theory to William Harvey's Theory: A Case Study in the Rationality of Scientific Theory Change. Studies in History and Philosophy of Science 1985; 16: 49-82.

Peirce CS. The Philosophy of Peirce. Selected Writings (ed. J Buchler). Routledge \& Kegan Paul. London 1956. 
Porter R. The Greatest Benefit to Mankind. A Medical History of Humanity from Antiquity to the Present. Fontana Press. London 1999.

Rosenthal J. Wahrscheinlichkeiten als Tendenzen. Eine Untersuchung objektiver Wahrscheinlichkeitsbegriffe. mentis Verlag. Paderborn 2002.

Sebeok TA, Umiker-Sebeok J. "You know my method": A Juxtaposition of Charles S Peirce and Sherlock Holmes. In Eco U, Seboek TA (eds). 'The Sign of Three. Dupin, Homes, Peirce.’ Indiana University Press. Bloomington 1983.

Semmelweis IP. Die Aetiologie, der Begriff und die Prophylaxis des Kindbettfiebers. Hartlen's Verlag-Expedition. Pest, Wien, and Leipzig 1861.

Sowa JF, Majundar AK. Analogical Reasoning. In Aldo A et al. (eds.). Conceptual Structures for Knowledge Creation and Communication. LNAI 2746. SpringerVerlag. Berlin 2003. 